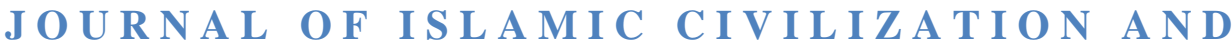
C U L T U R E ( J I C C )

Volume 3, Issue 1 (Jan-June, 2020)

ISSN (Print):2707-689X

ISSN (Online) 2707-6903

Issue: http://ahbabtrust.org/ojs/index.php/jicc/issue/view/8

URL: http://ahbabtrust.org/ojs/index.php/jicc/article/view/90/94

Article DOI: https://doi.org/10.46896/iicc.v3i01.90

Title

Analytical Review of Noel James

Coulson Book's A History of Islamic Law

Author (s): $\quad$ Dr. Muhammad Ilyas, Dr. Zainab Ameen

Received on: $\quad$ 29 June, 2019

Accepted on: 29 May, 2020

Published on: $\quad 25$ June, 2020

Citation:

Dr. Muhammad Ilyas and Dr. Zainab Ameen, "Construction: Analytical Review of Noel James Coulson Book's A History of Islamic Law," JICC: 3 no, 1 (2020): 168-190

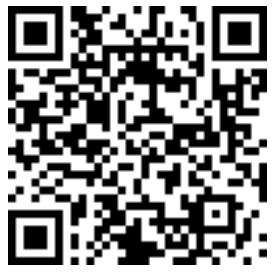

Islamic Reseach Index Hat

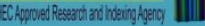

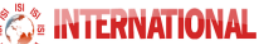

scientific
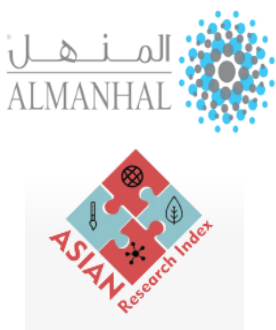

Crossref

Publisher: $\quad$ Al-Ahbab Turst Islamabad 


\section{Analytical Review of Noel James Coulson Book's A History of Islamic Law}

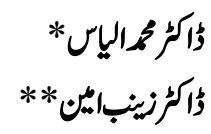

\section{Abstract}

The Western Orientalism movement had resulted in the creation of a large academic asset of Islamic literature. The Orientalists had struggled in two ways; by introducing and editing old Islamic manuscripts, and by commenting on the various aspects of the Prophet's (PBUH) life and his traditions. Moreover, some Orientalists had worked on the Islamic jurisprudence, too. As Coulson, have been discussed analytical studies of Islamic jurisprudence, in this regard his book, " The History of Islamic Law", is a sorely needed book; it will substantiate a highly impactful, direly beneficial and effective book; and above all, it is a remarkably wellconstructed book.

Mr. Coulson's compact volume is a clear, comprehensive, and authoritative treatment of the genesis and history of Islamic law in theory and practice, and of the central problem of legal reform now confronting Muslim society. Islamic law, the Sharia of medieval Islam, is for Muslims and the comprehensive catalogue of God's commands and recommendations laid down for the guidance of man... In recent times, with the wholesome adoption by Muslim countries of western legal ideas and institutions, the Sharia has seemingly been all but forsaken and abandoned... Unless the idea of a law system based on religion is to be abandoned entirely... [Coulson] points out, the task for modern Muslims, like that of their medieval predecessors, is once more to ascertain and impose the central ethical criterion norms of Islam upon the functioning's of their society. $N$. J. Coulson was a chair of oriental laws at the School of Oriental and African Studies, University of London. In this article the analytical and critical review is discussed.

Key word: N. J. Coulson book A history of Islamic Law analytical Critical review

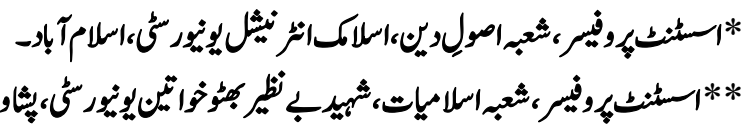




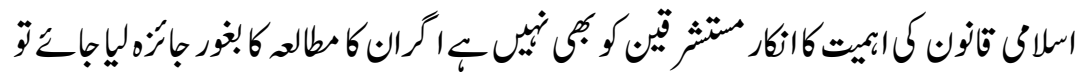

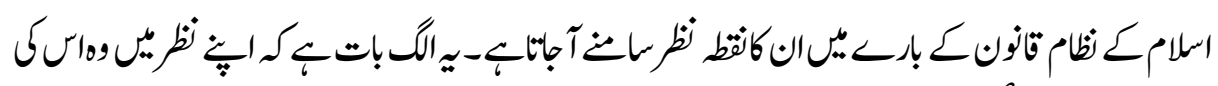

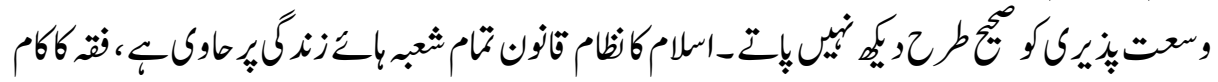

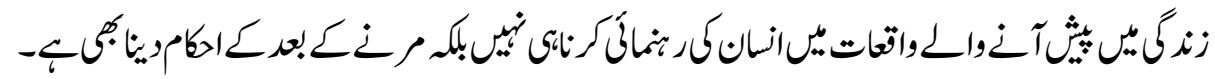

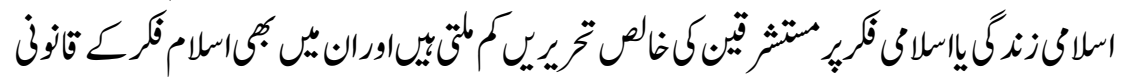

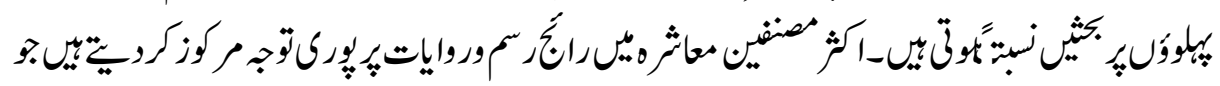

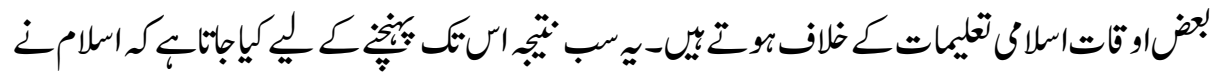

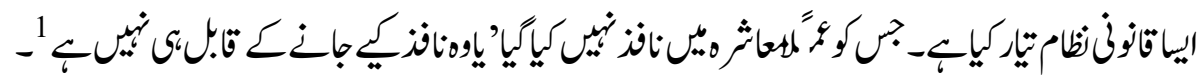

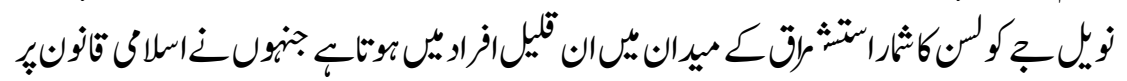

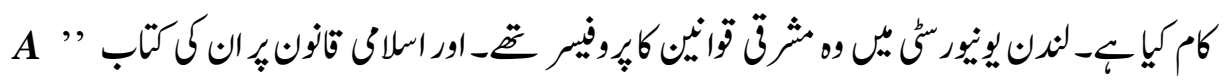

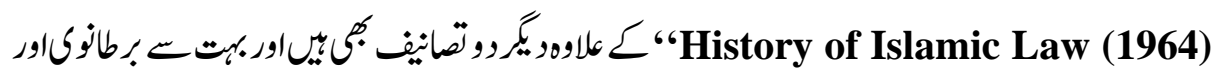

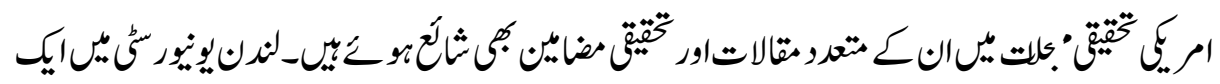

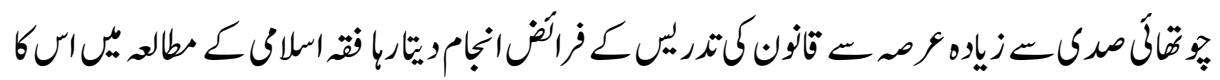

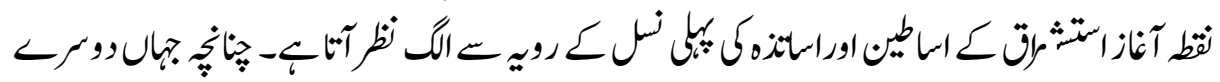

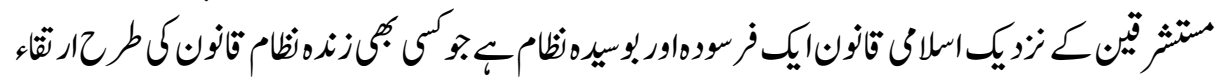

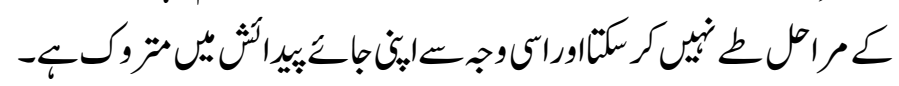

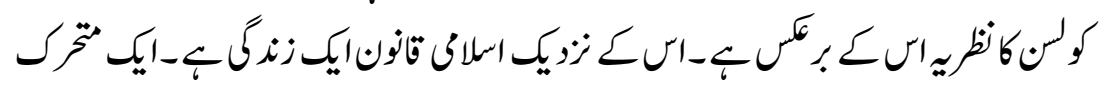

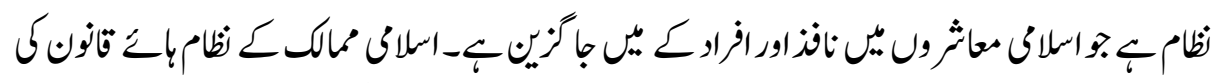

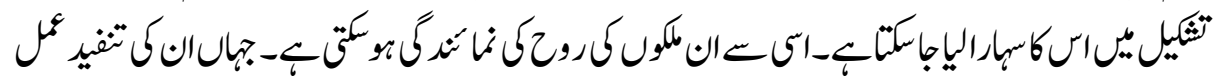

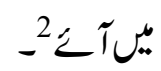

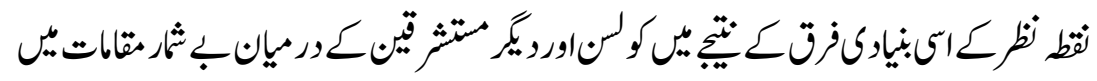

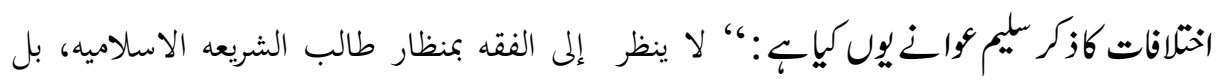

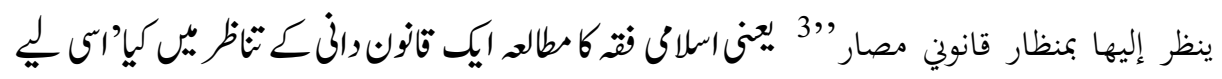

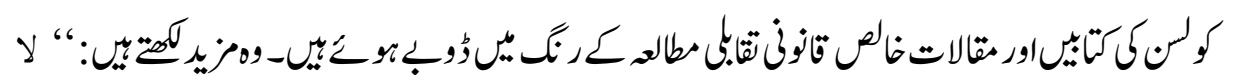




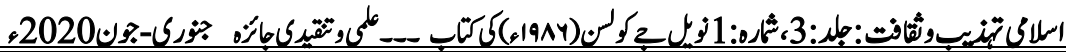

وجهة البحث العلمي في خدمة السياسة كما يغلب علي كثير من المستشرقين....... "بلئناسك

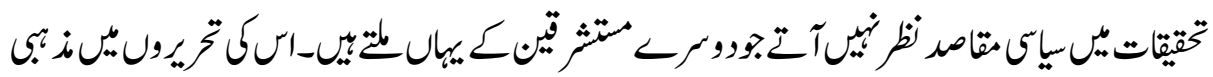

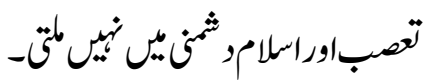

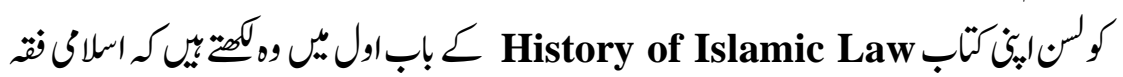

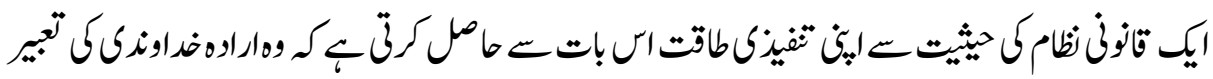

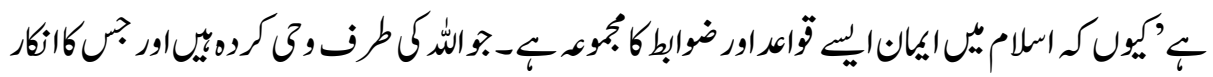

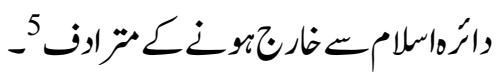

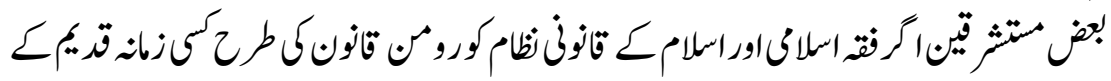

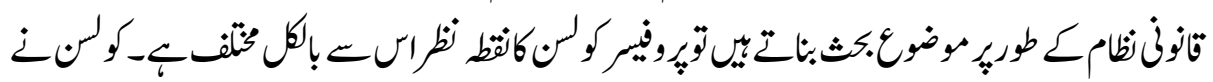

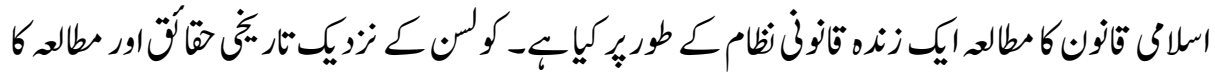

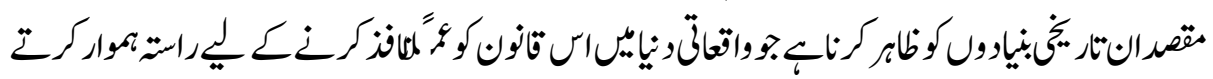

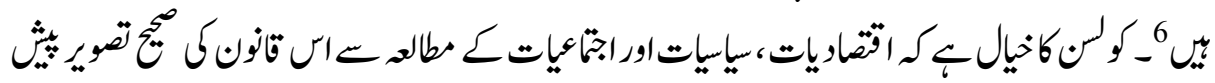
كرك

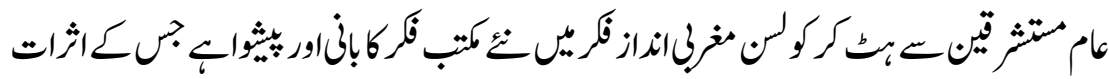

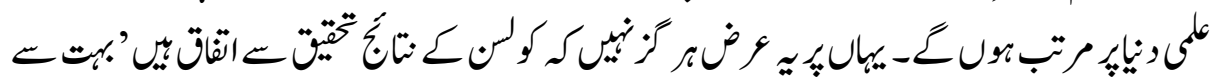

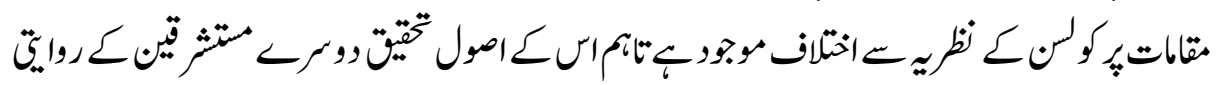

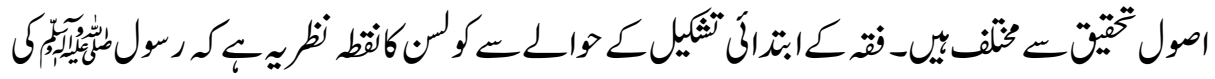

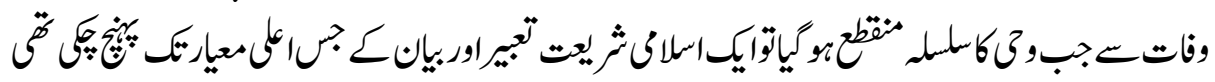

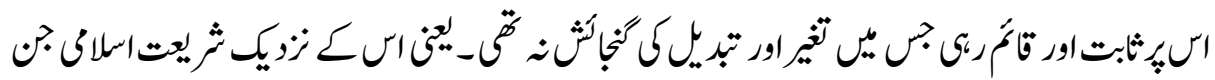

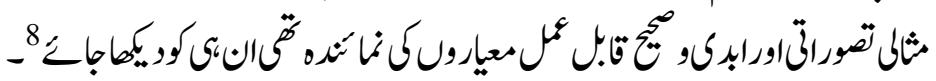

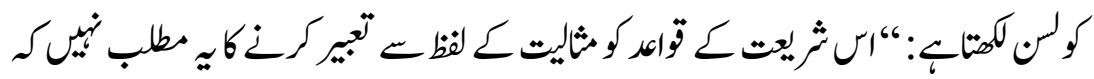

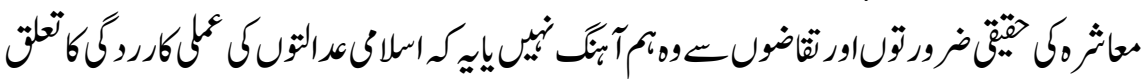

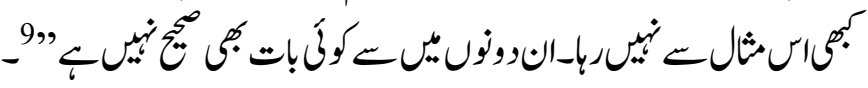




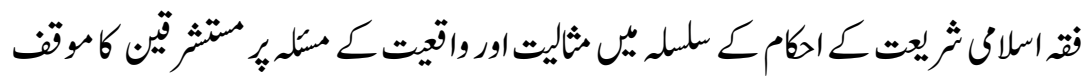

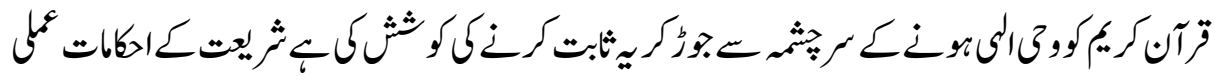

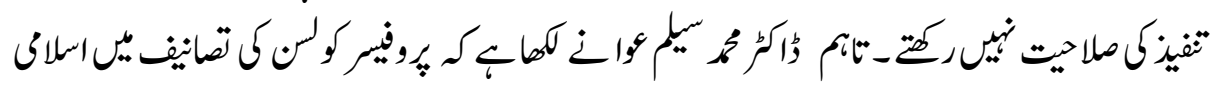

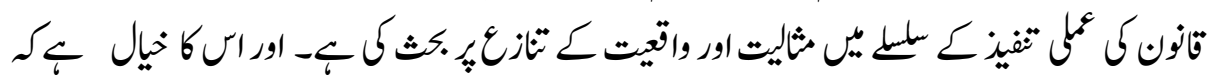

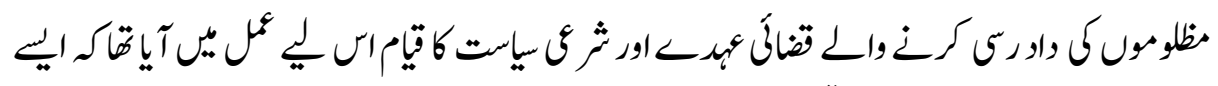

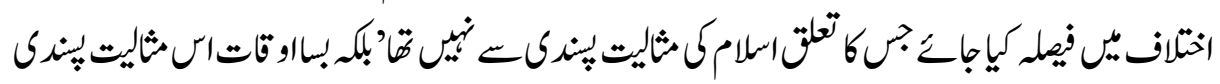

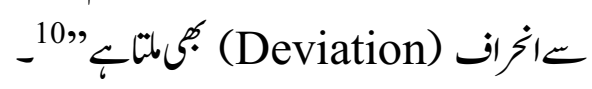

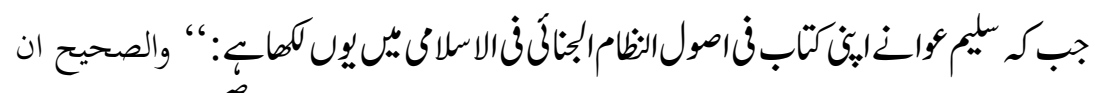

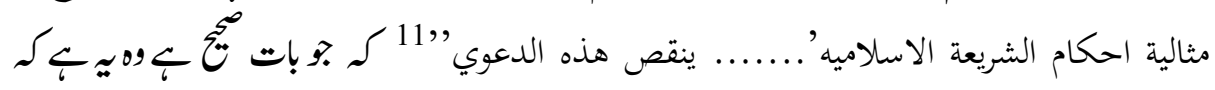

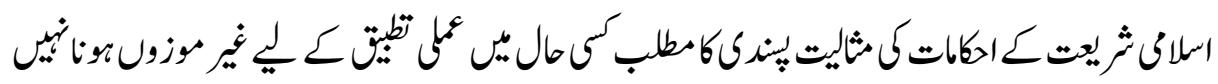

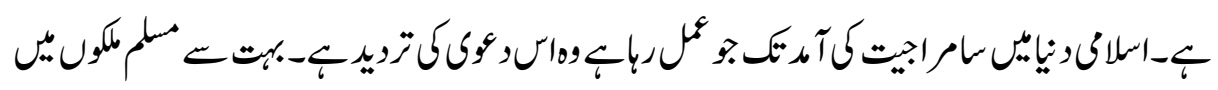

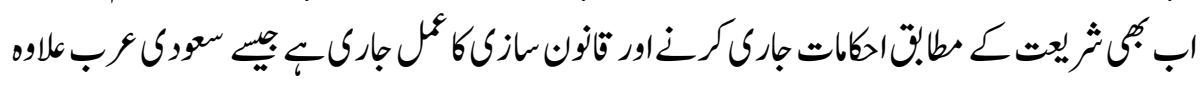

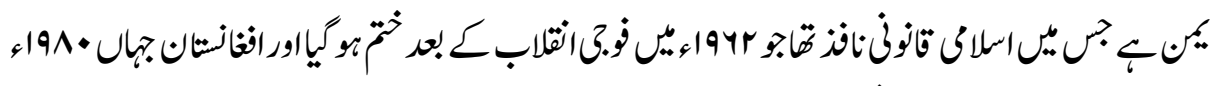

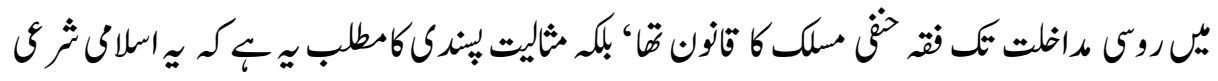

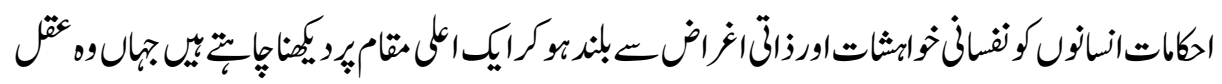

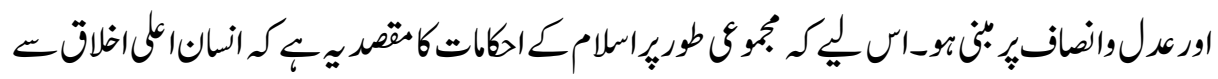

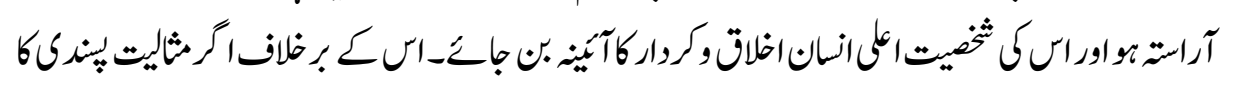

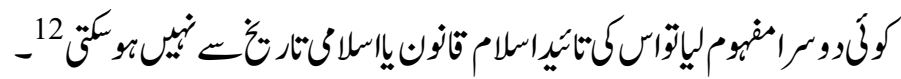

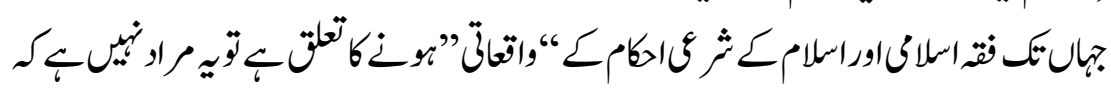

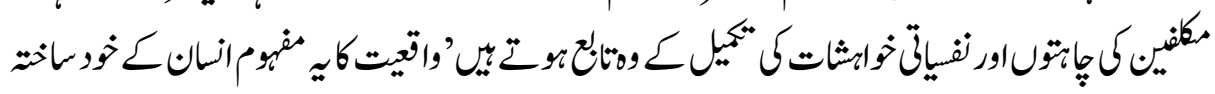

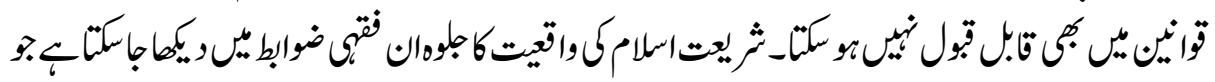

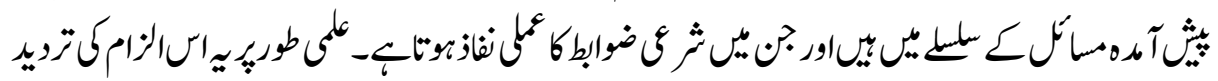

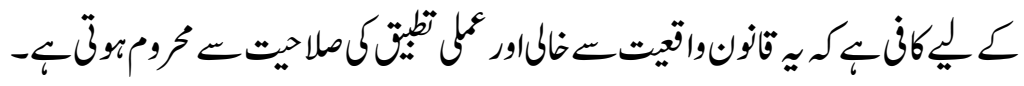




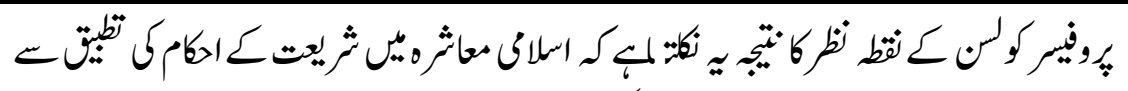

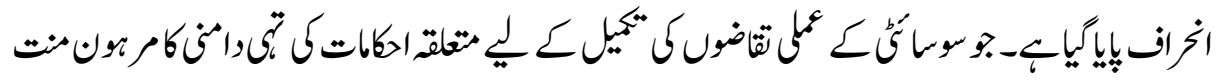

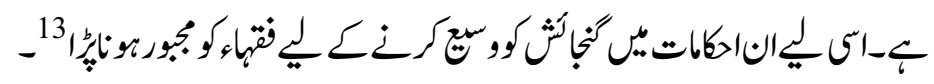

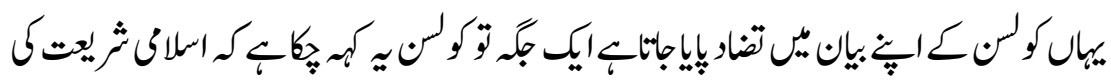

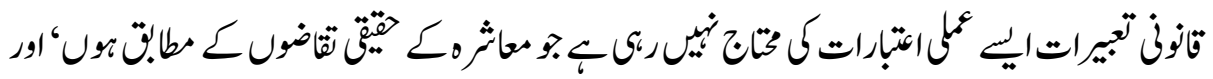

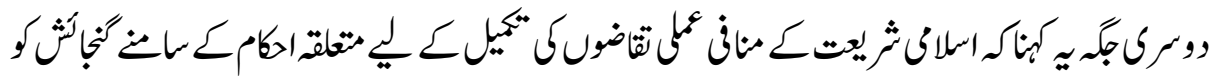

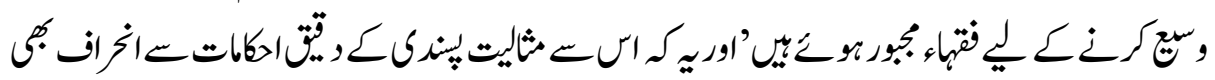

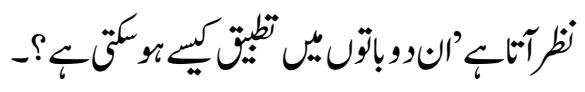

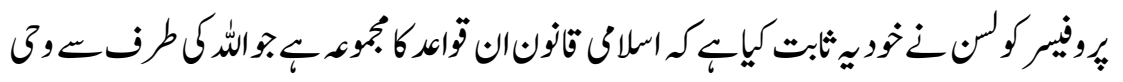

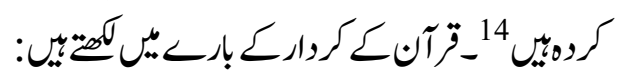

"In the Qur'anic Revelations came to supersede tribal custom in varicose respects... 15 .

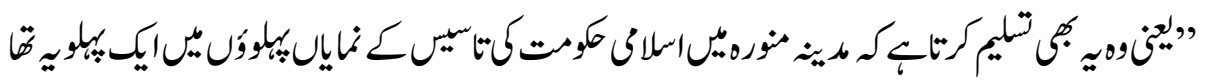

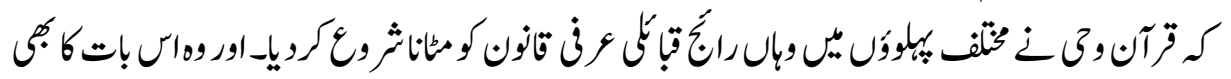

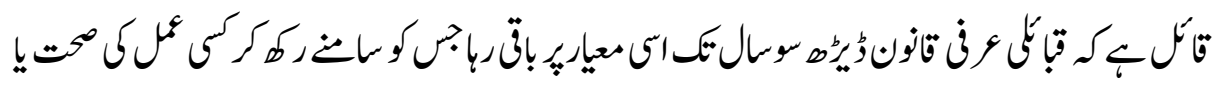

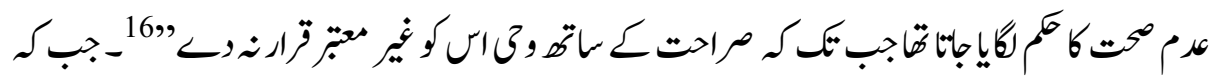

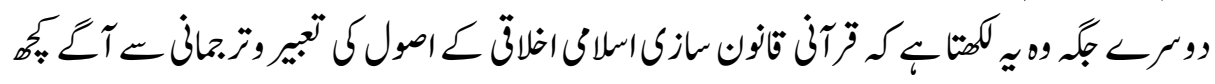

$$
\text { - } 17,
$$

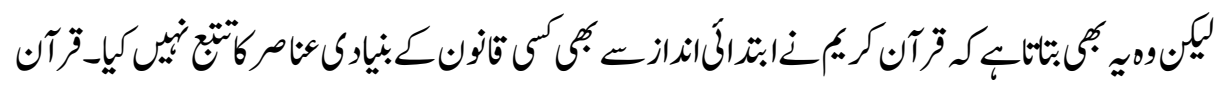

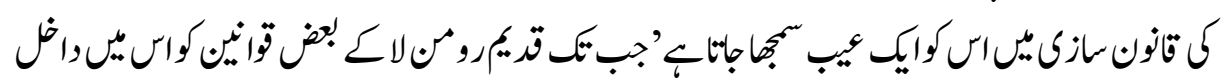

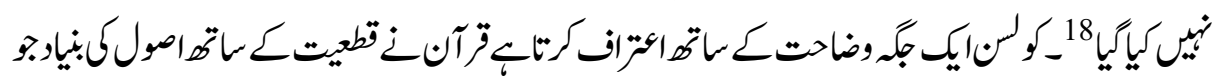

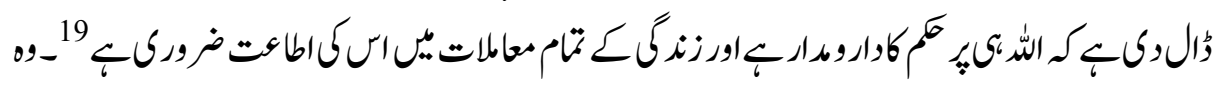

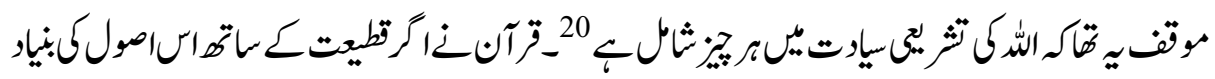

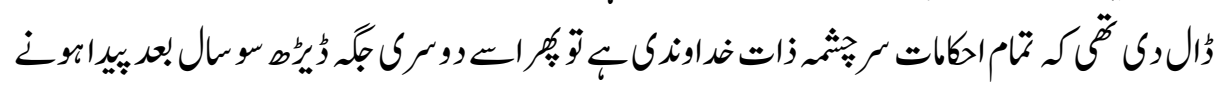

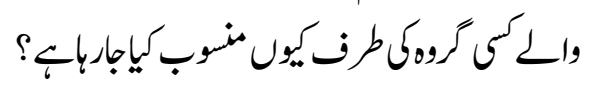




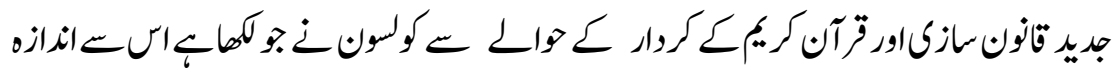

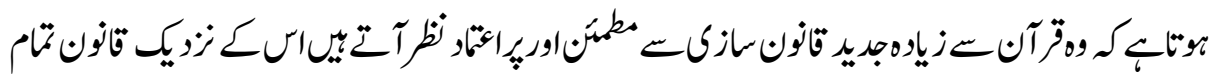

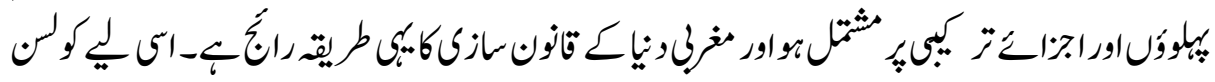

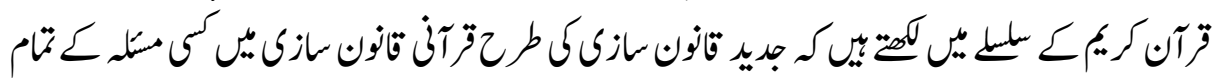

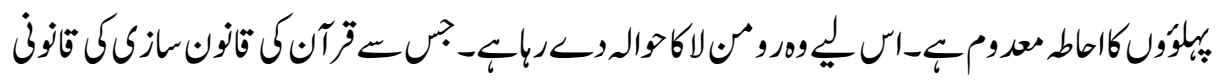

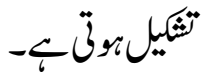

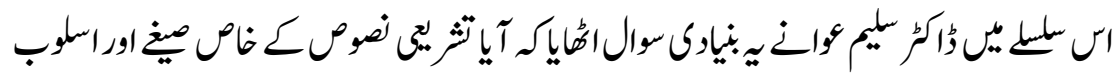

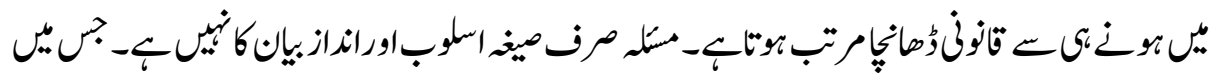

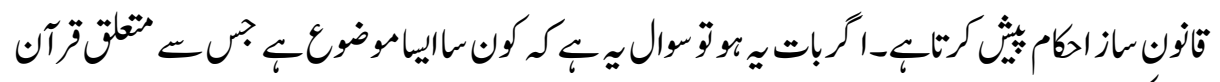

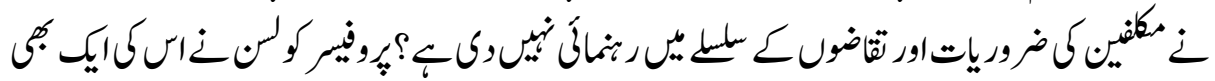

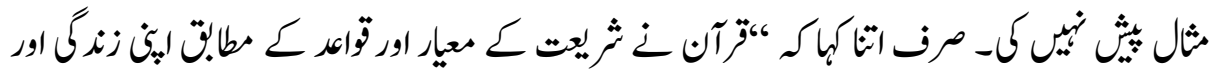

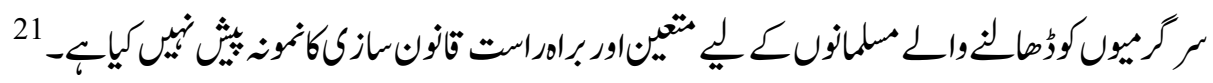

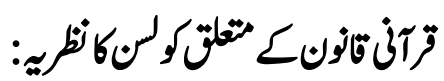

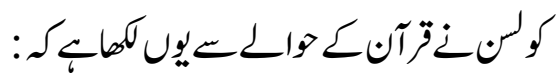

"While the Qur'anic legislation, then, is predominantly ethical in quality, the quantity is not great by any standards. 22 ،

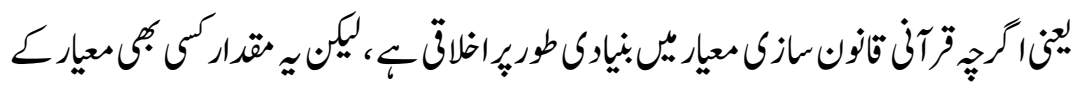

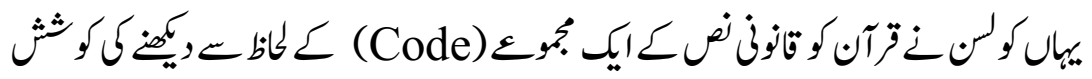

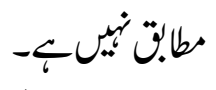

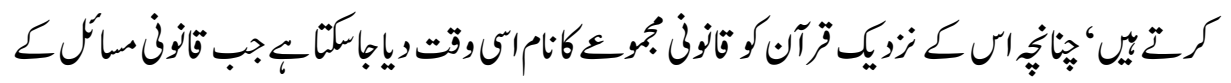

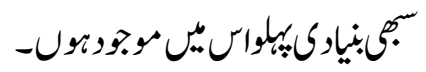

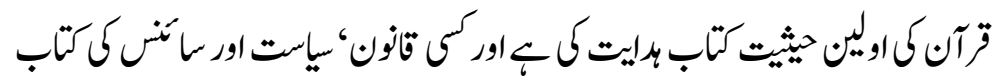

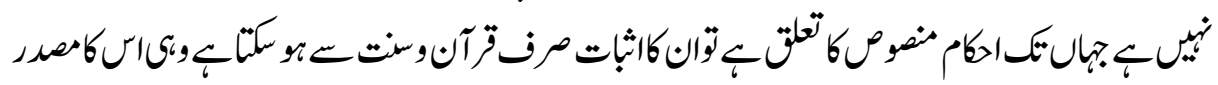

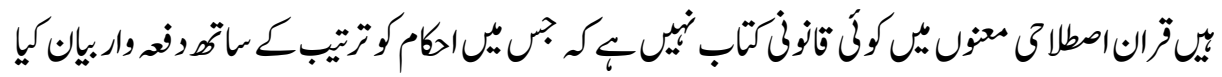




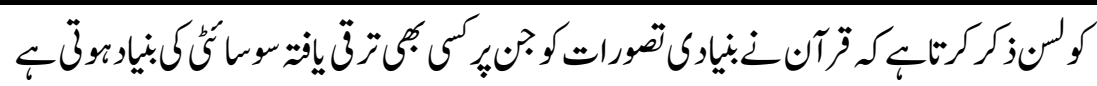

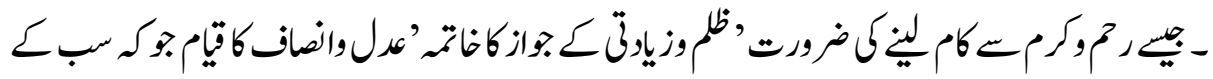

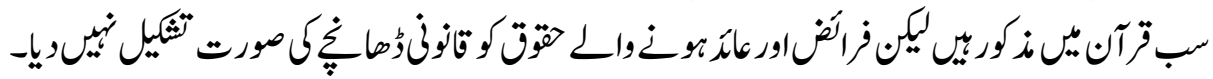

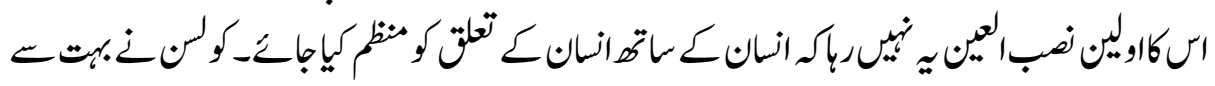

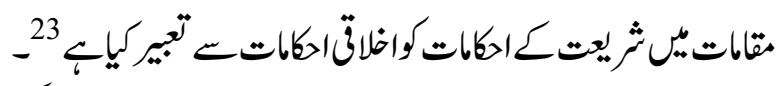

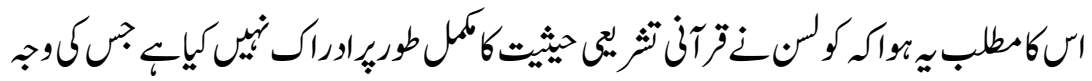

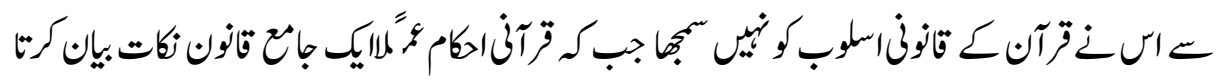
:

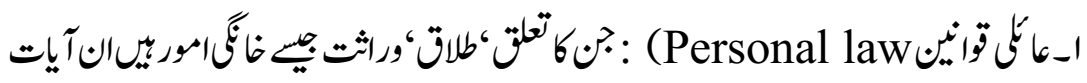

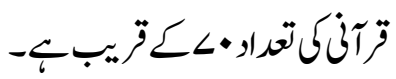

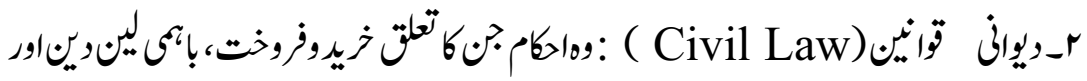

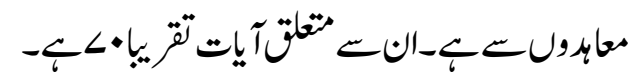

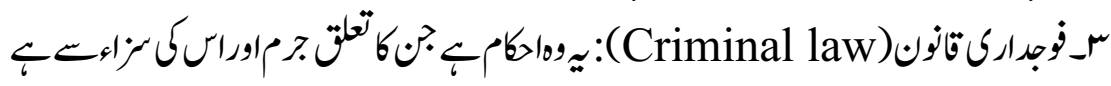

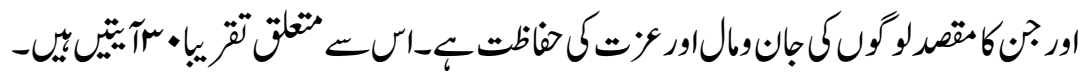

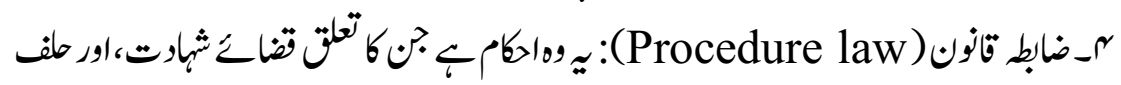

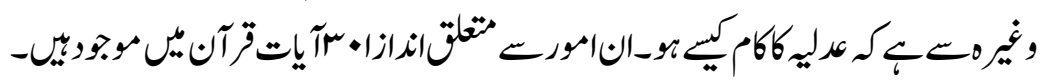

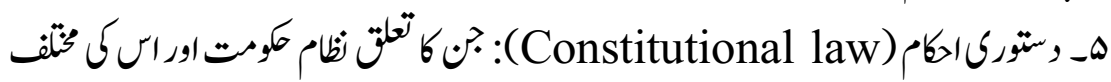
تضيلات ك-

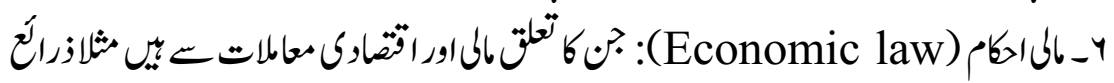

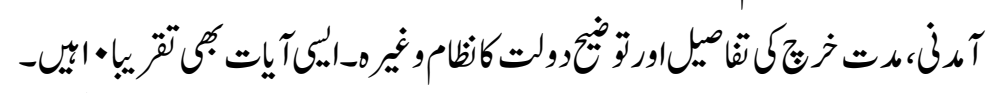

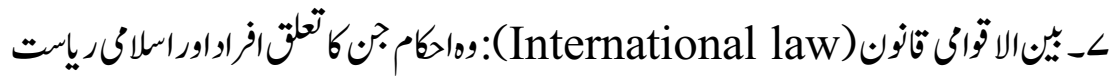

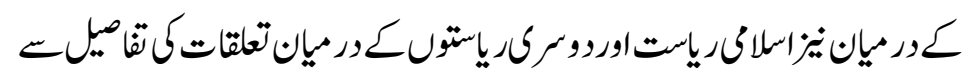

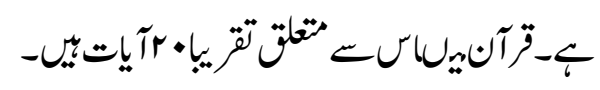

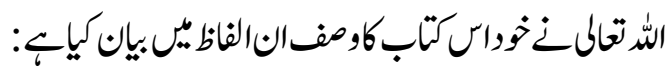




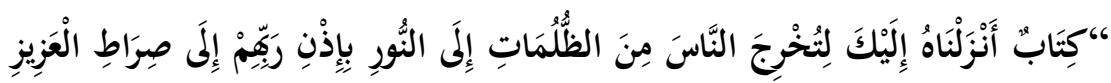

الحَمِيدِ

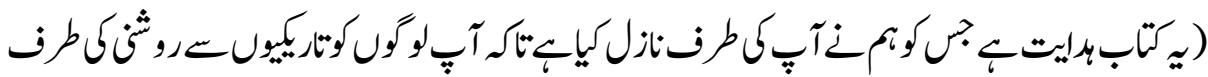

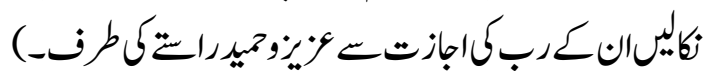

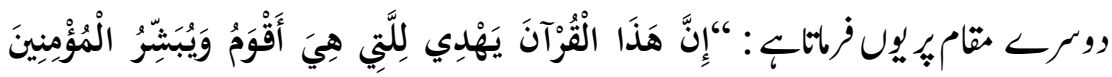

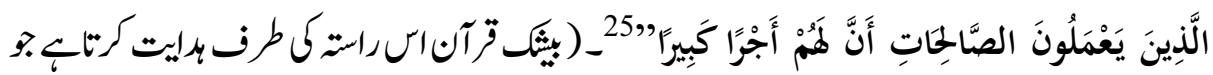

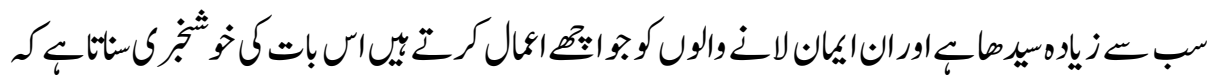

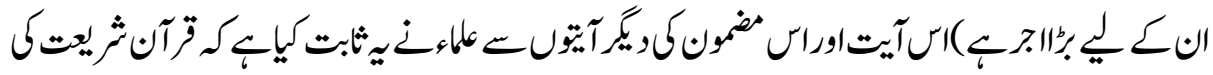

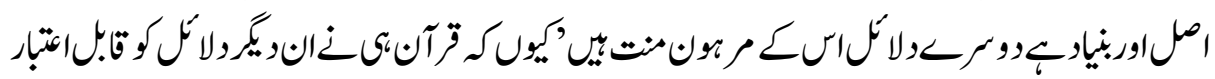

$$
\text { تراروياك }
$$

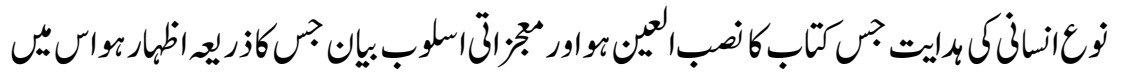

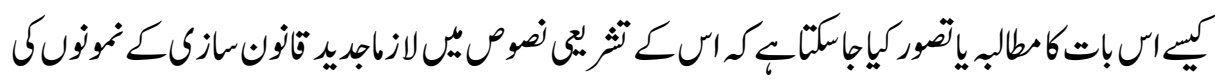

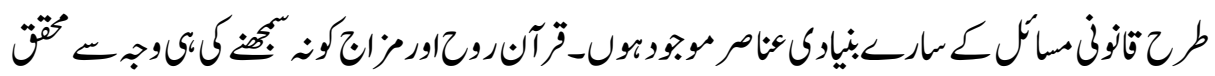

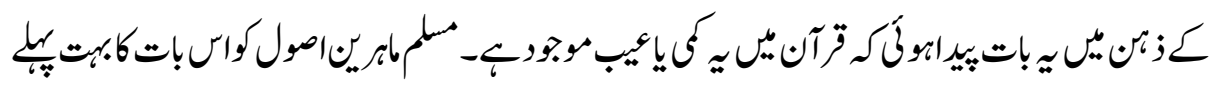

س

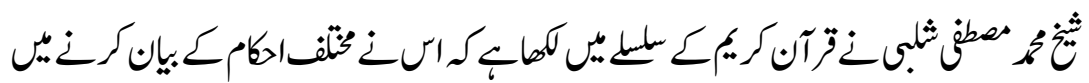

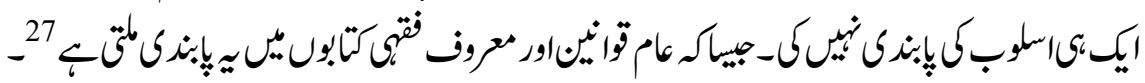

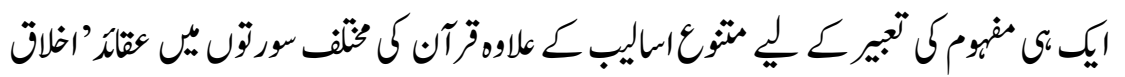

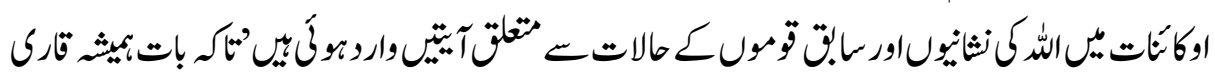

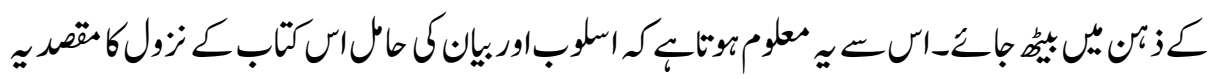

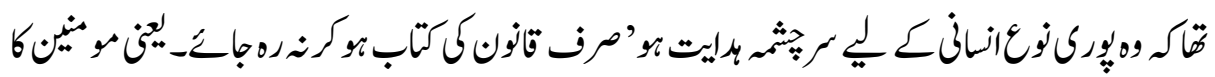

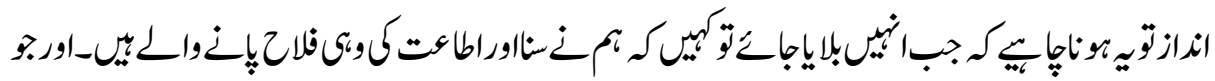

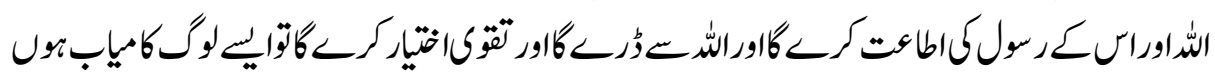




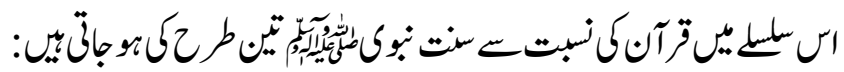

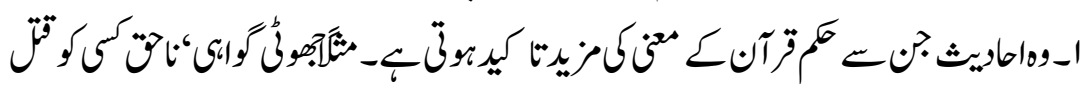

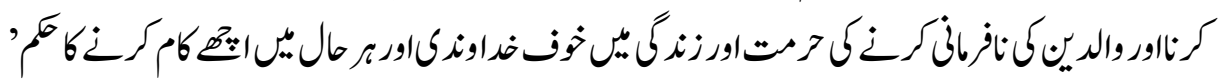

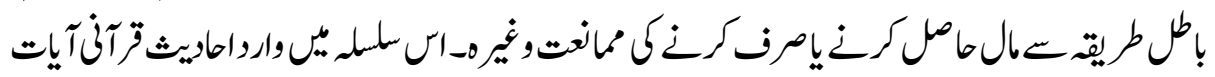

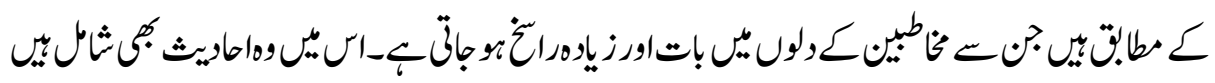

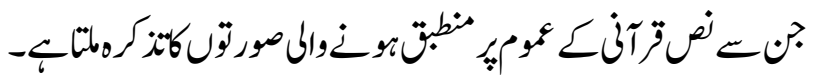

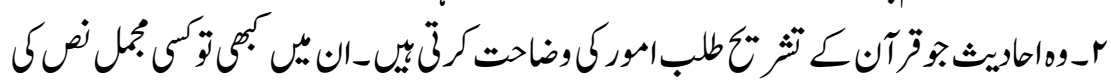

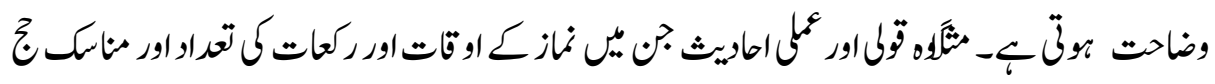

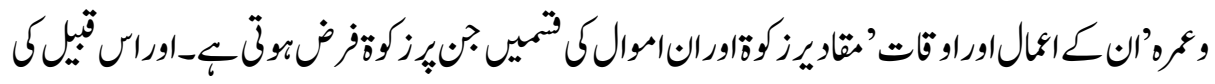

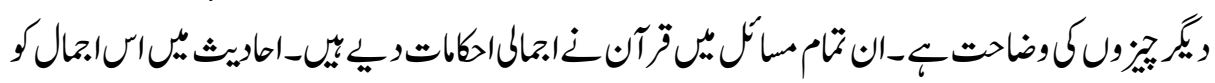

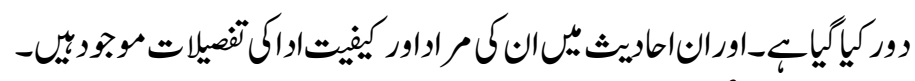

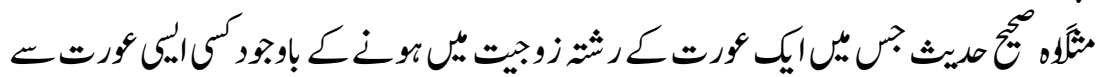

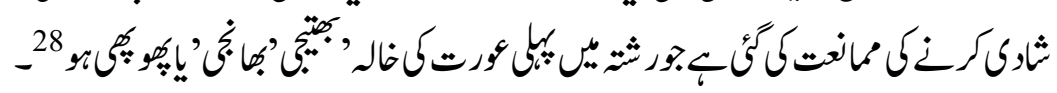

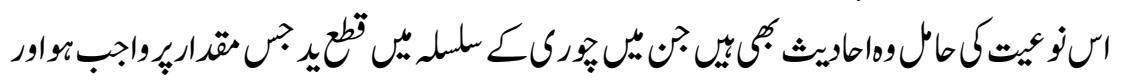

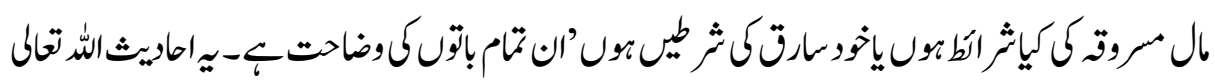

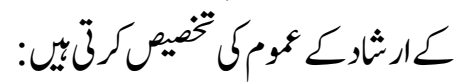

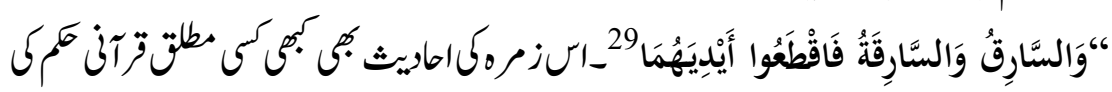

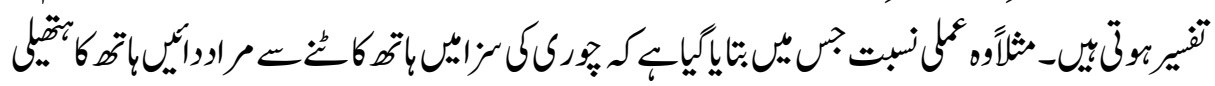

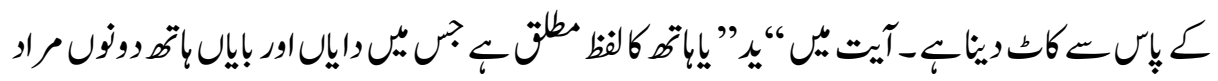

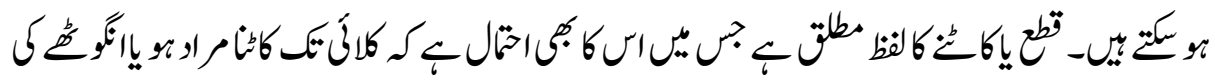

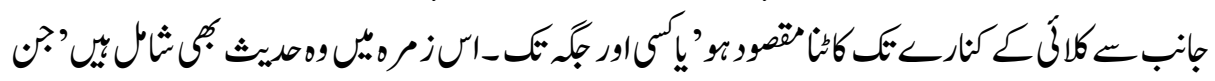

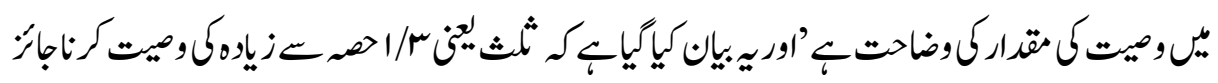

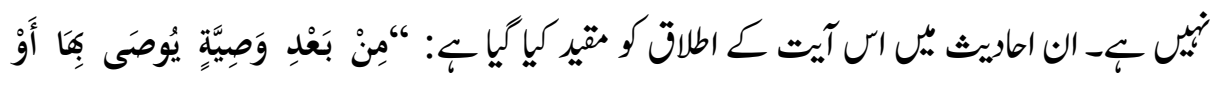
دَيْنِ 


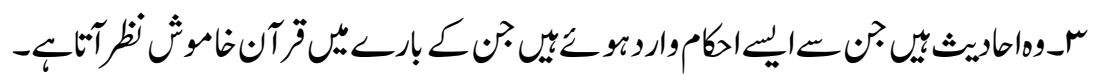

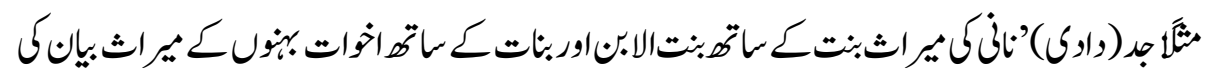

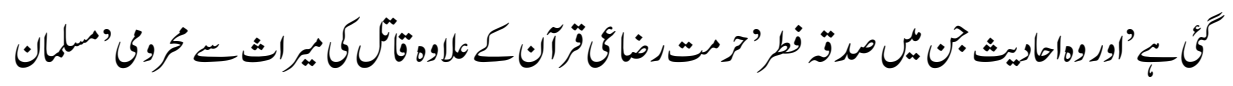

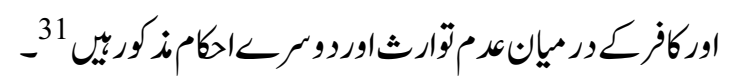

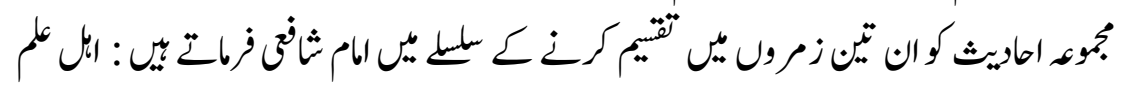

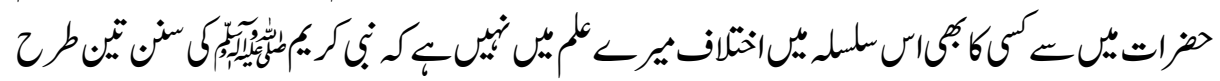

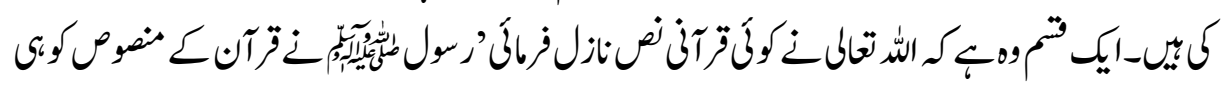

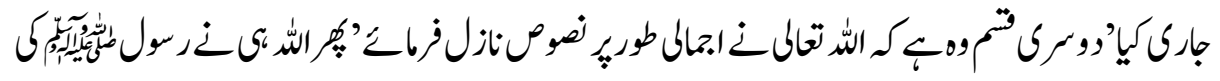

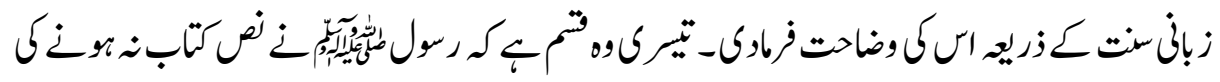

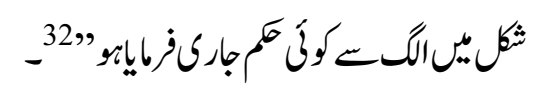

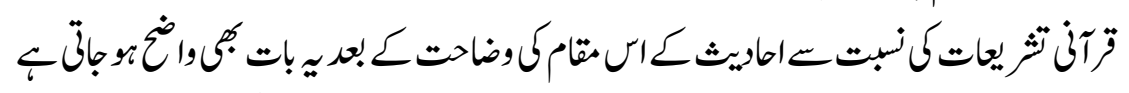

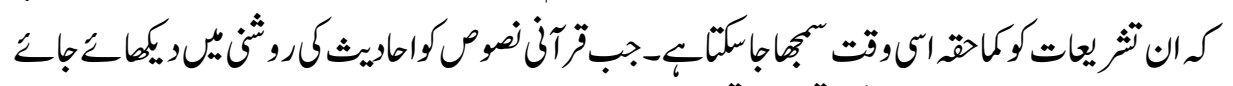

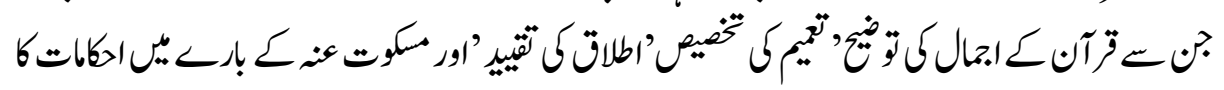

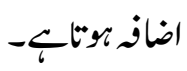

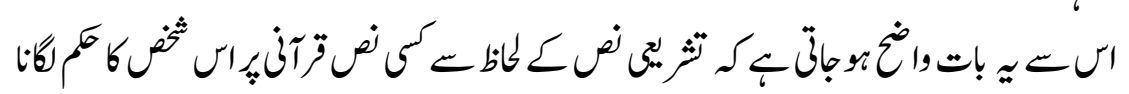

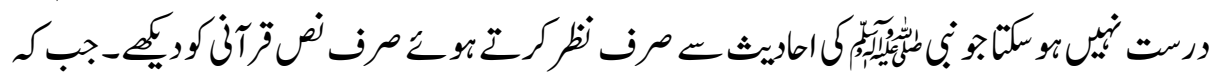

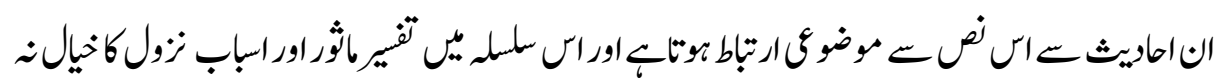

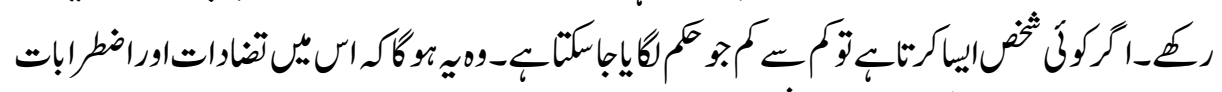

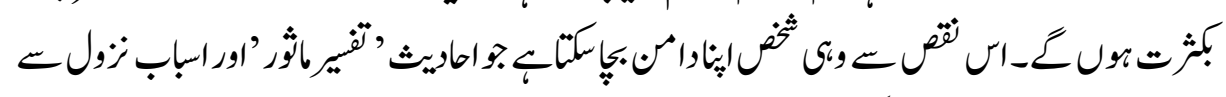

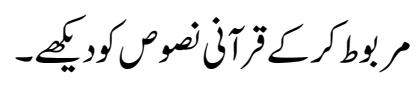

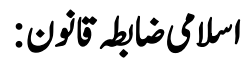

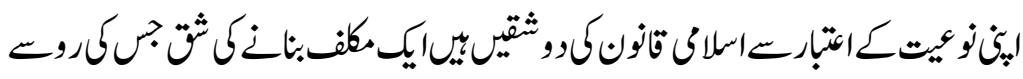

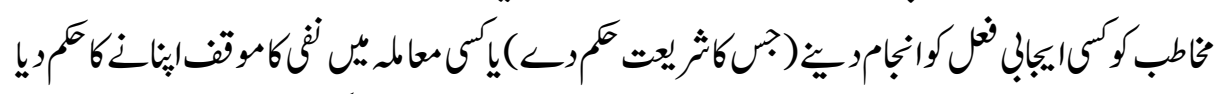

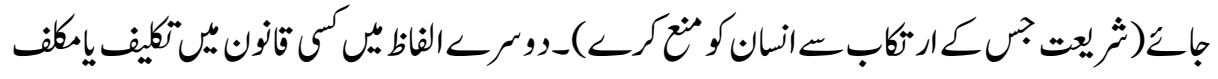




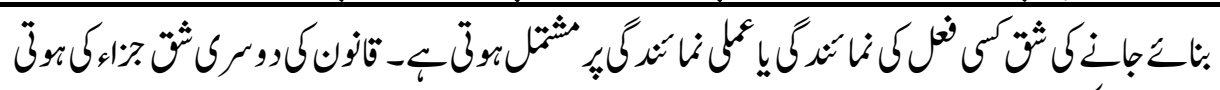

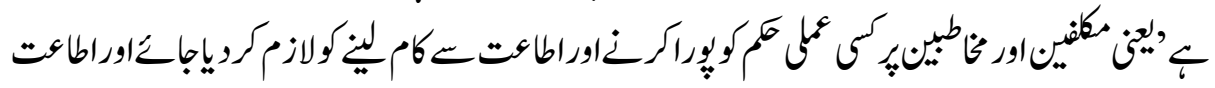

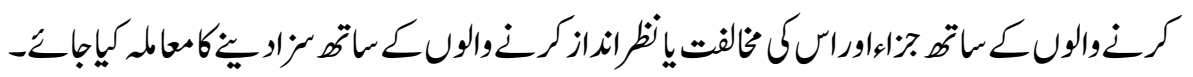

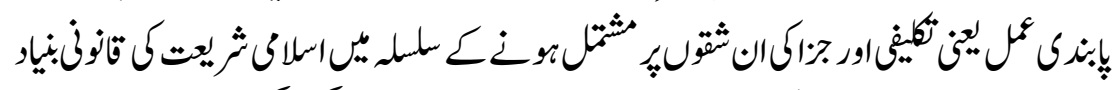

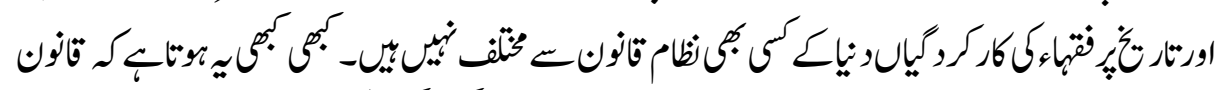

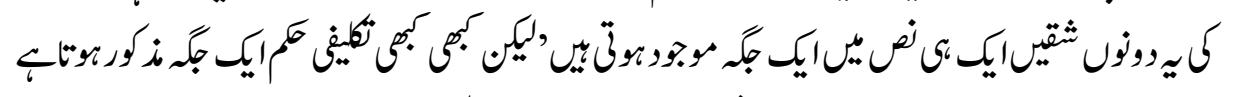

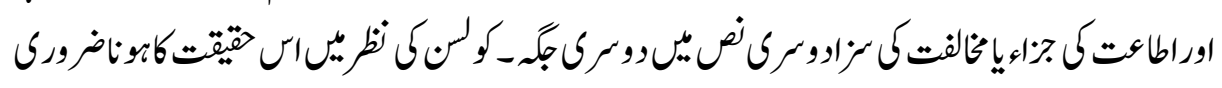
$-33 \ddot{\circ}$

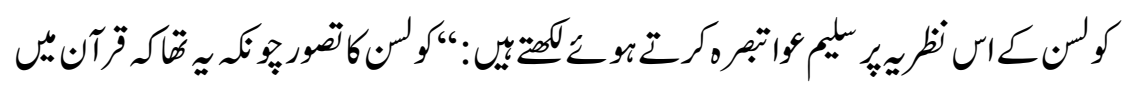

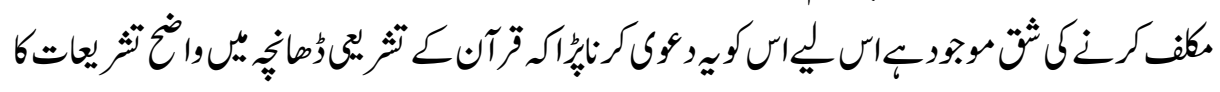

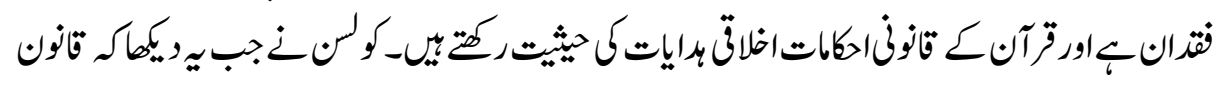

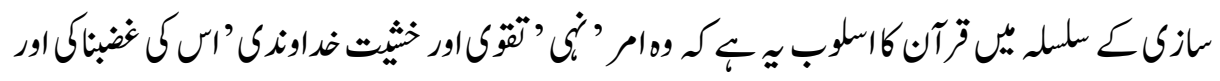

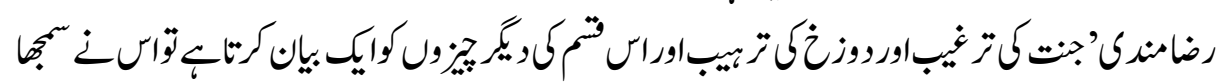

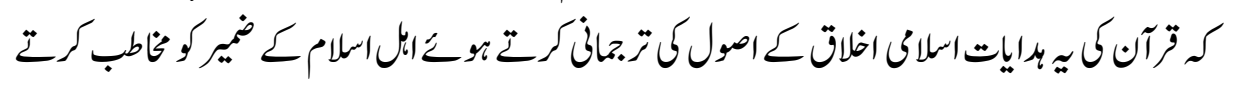

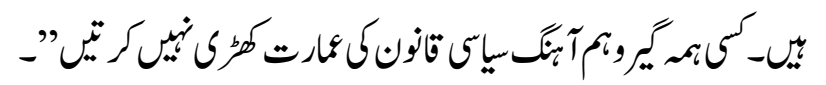

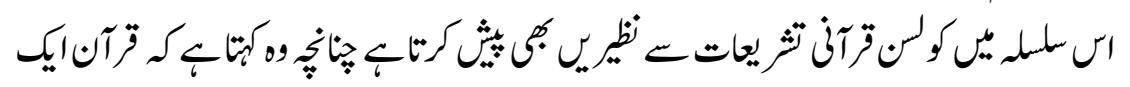

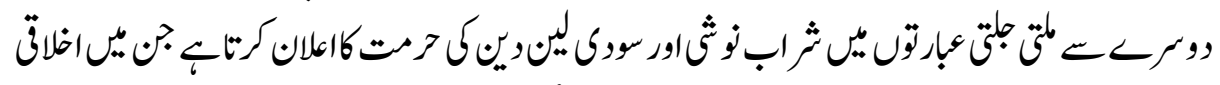

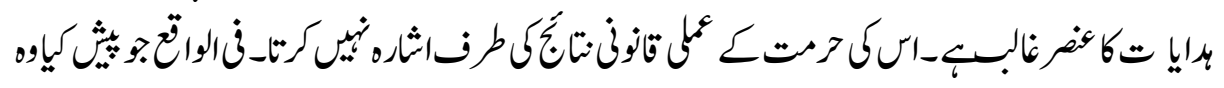

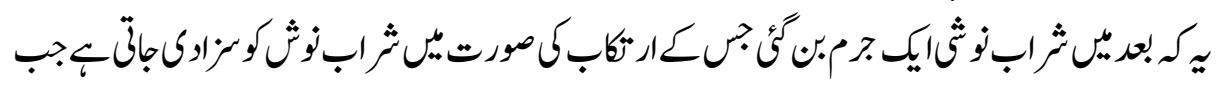

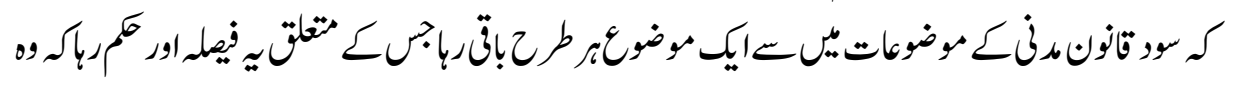

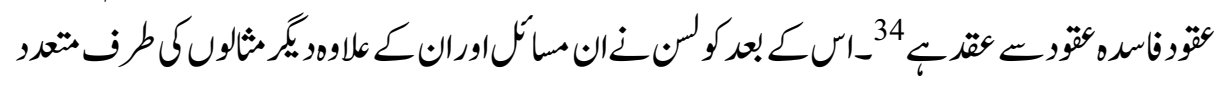

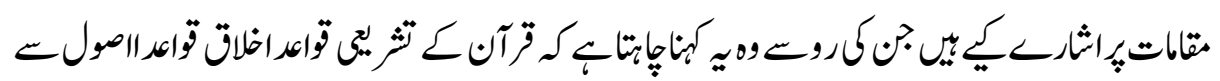

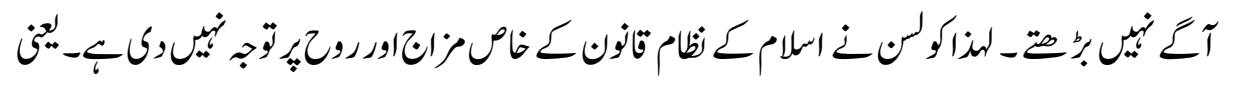

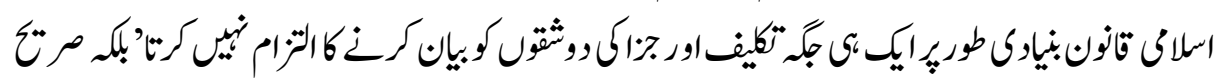




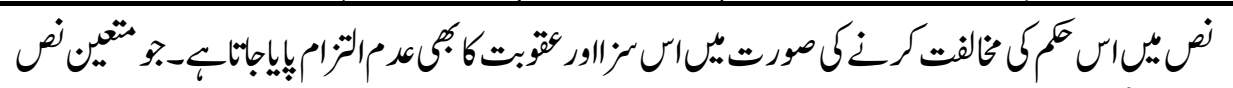

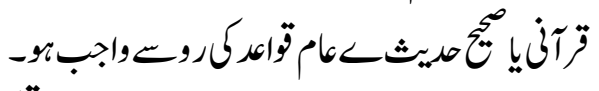

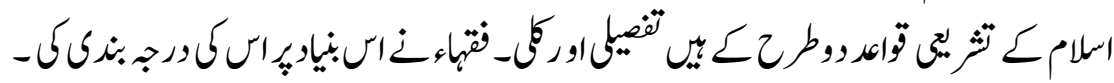

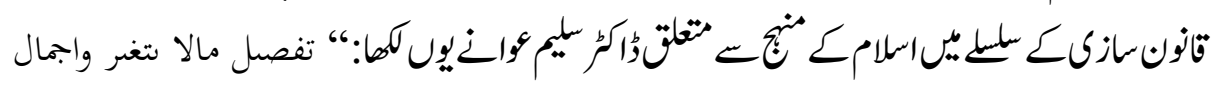

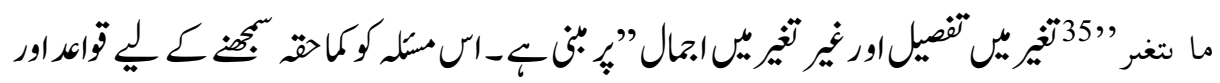

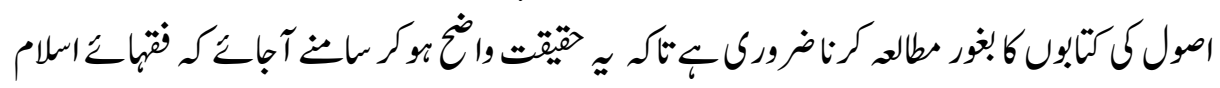

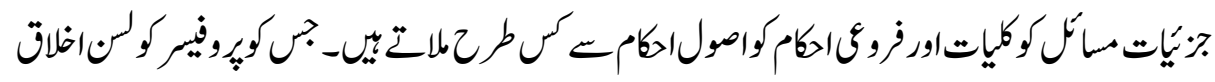

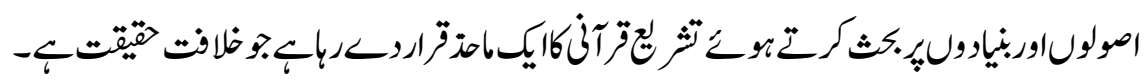

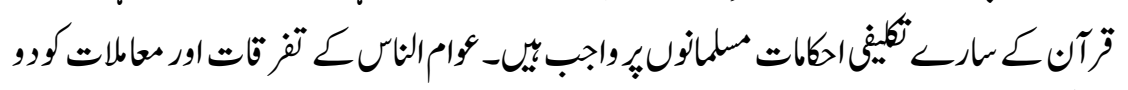

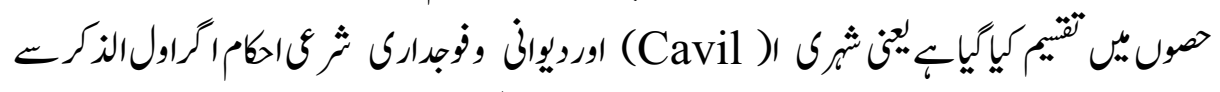

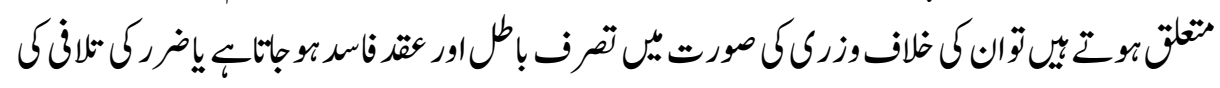

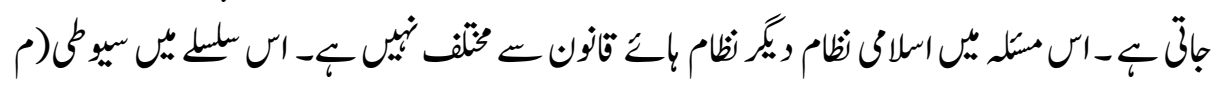

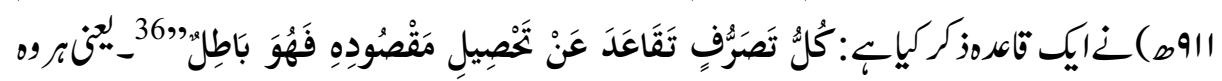

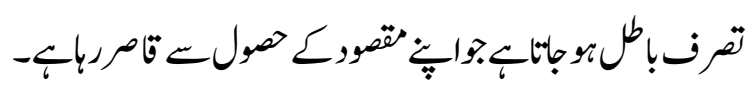

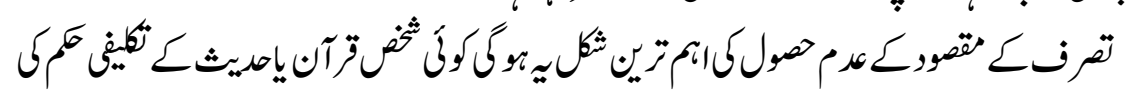

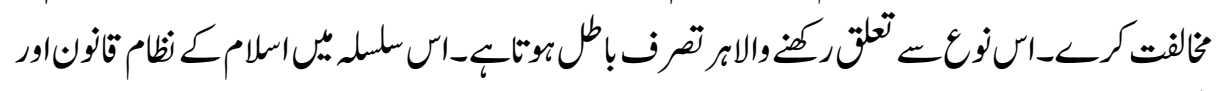

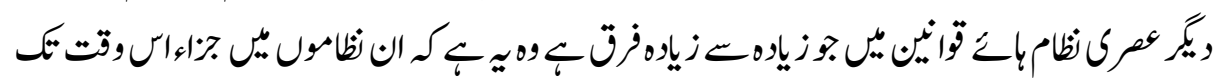

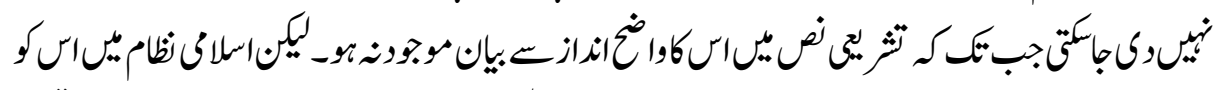

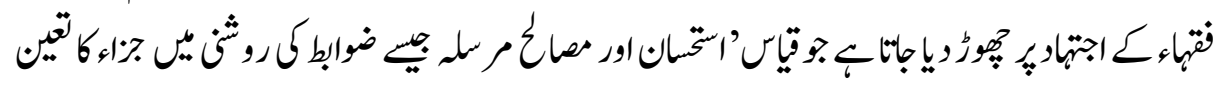

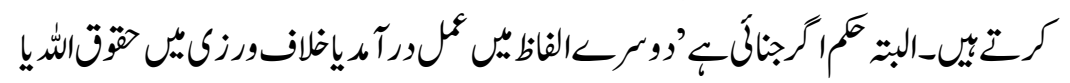

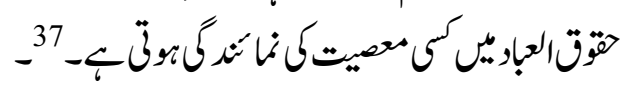

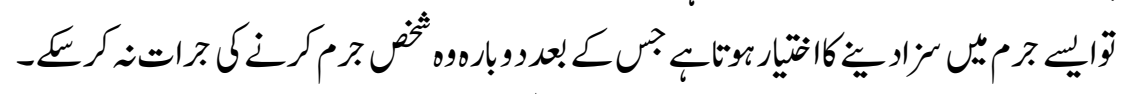

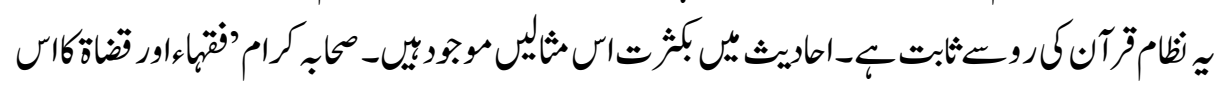
كُ 


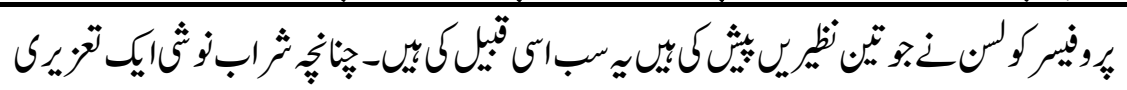

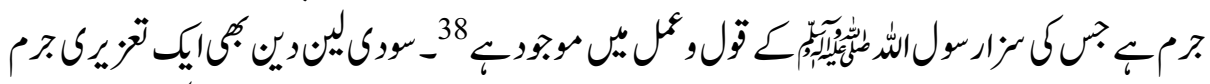

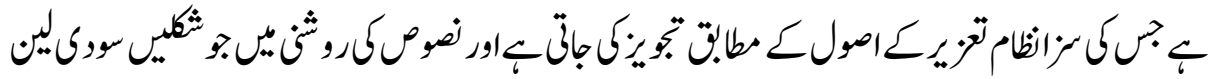

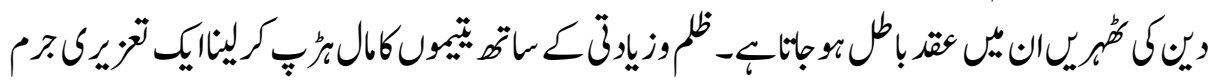

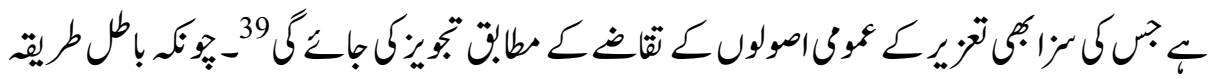

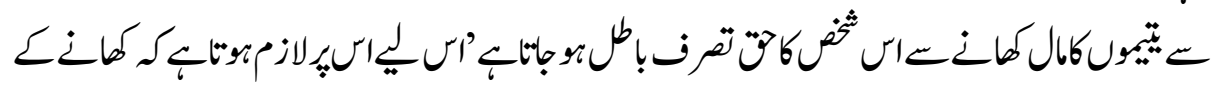

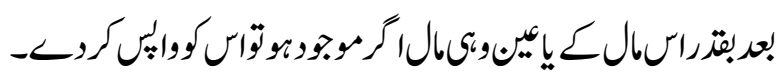

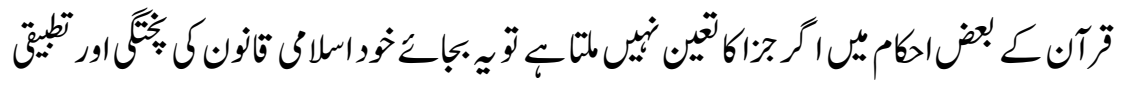

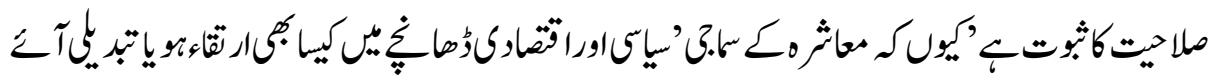

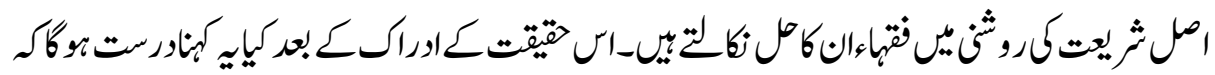

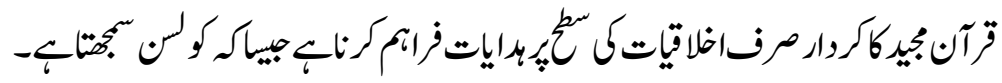

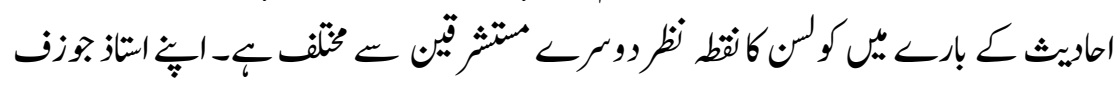

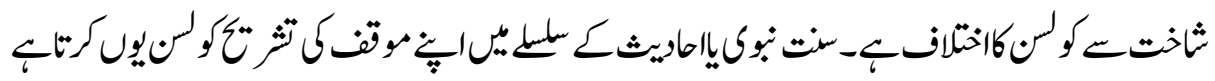

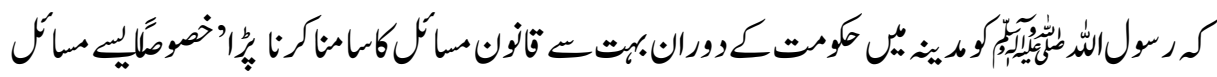

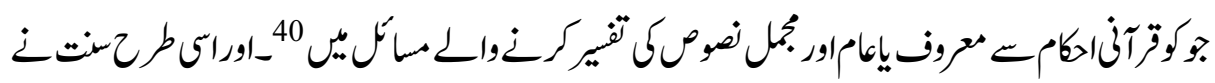

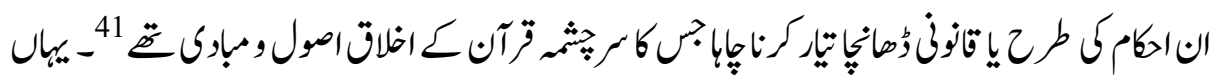

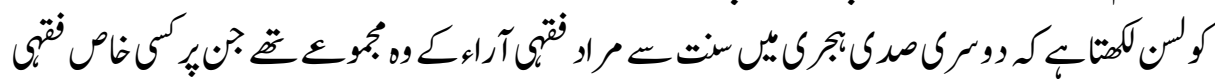

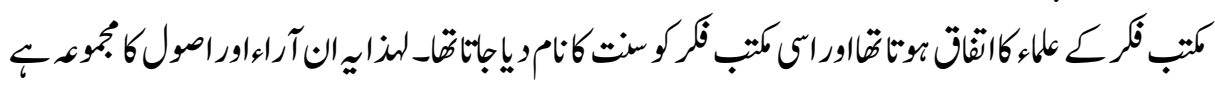

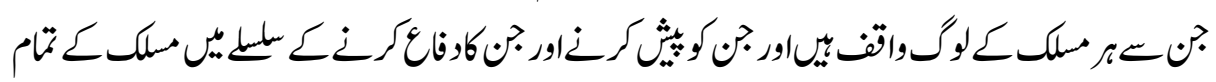

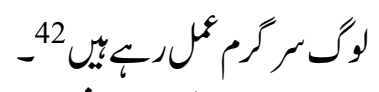

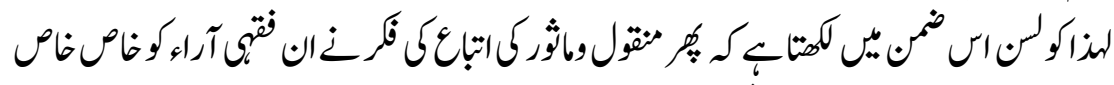

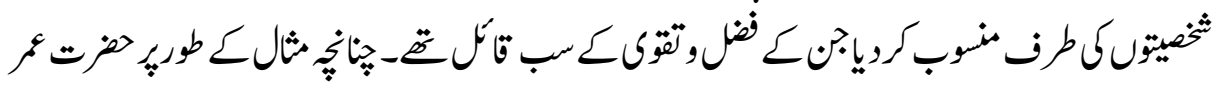

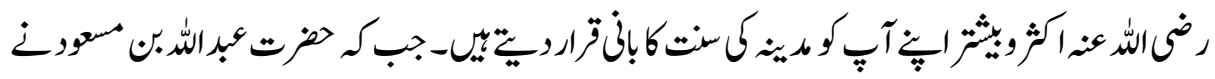




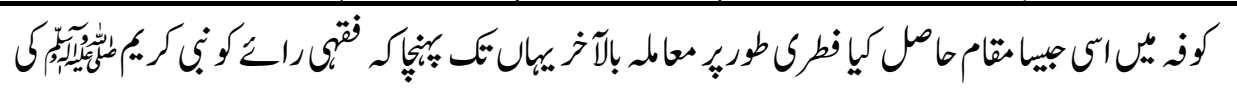

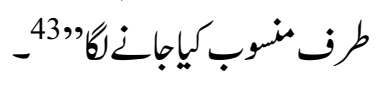

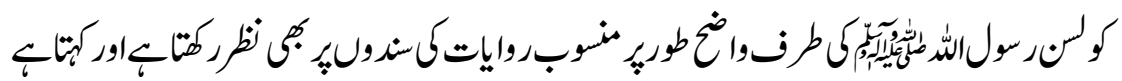

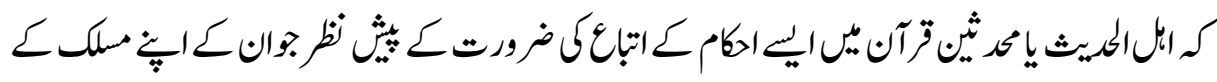

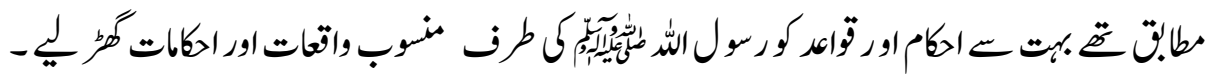

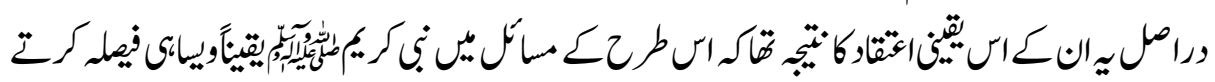

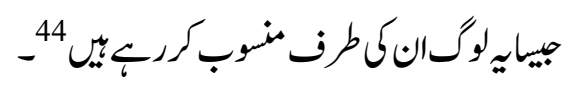

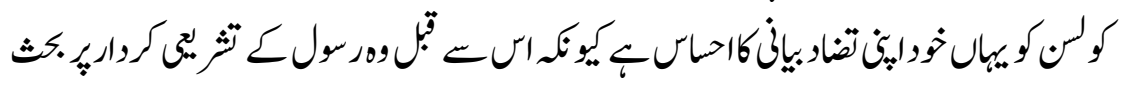

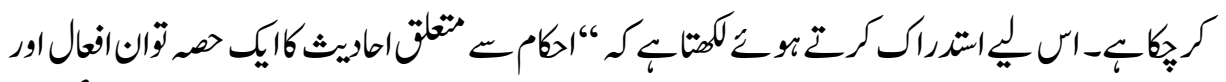

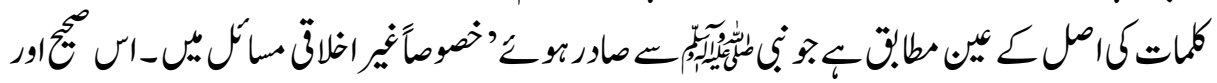

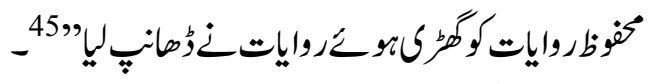

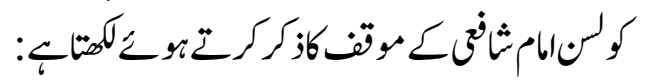

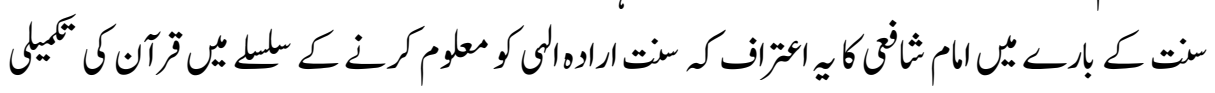

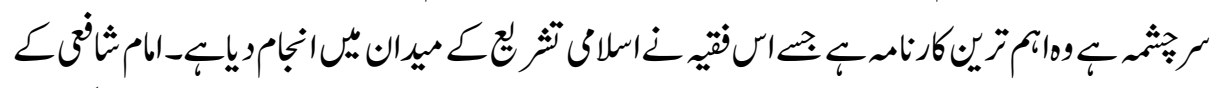

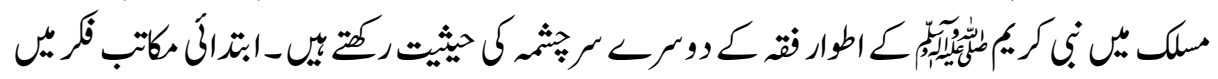

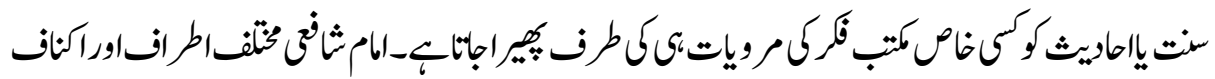

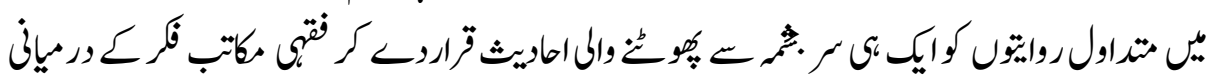

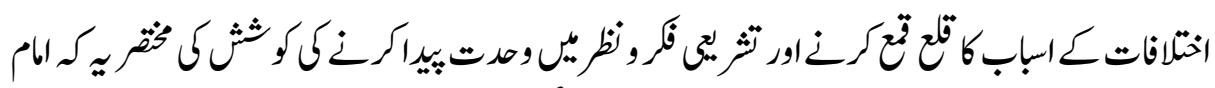

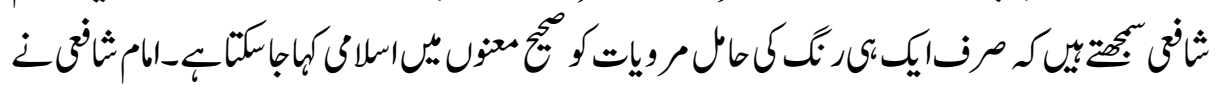

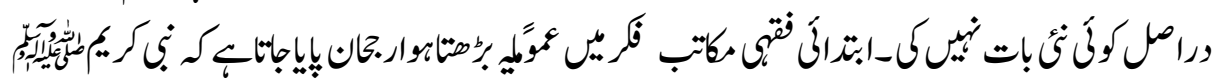

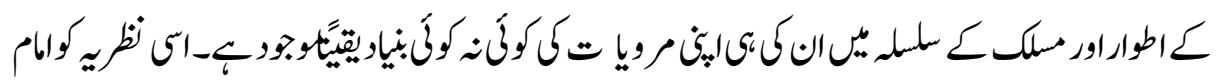

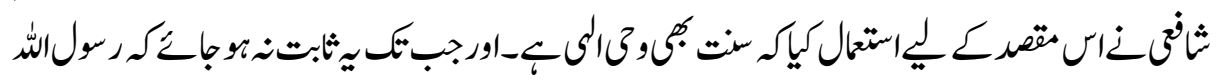

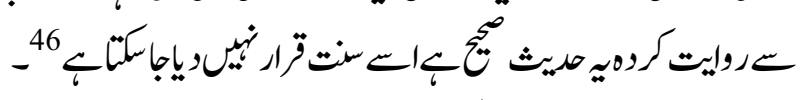

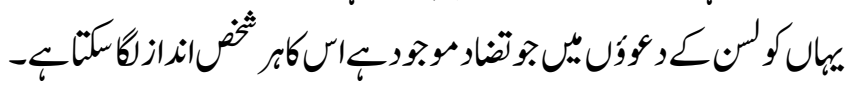




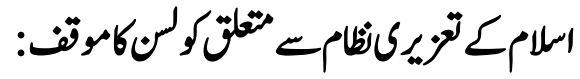

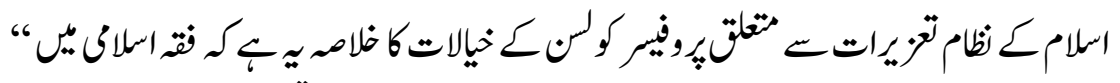

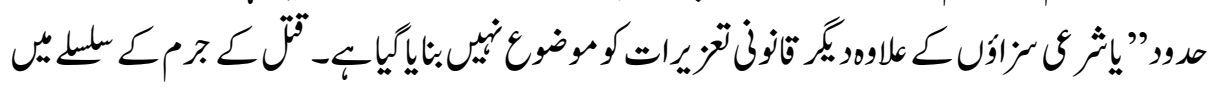

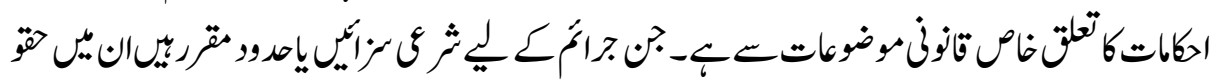

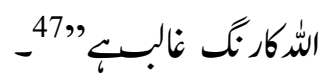

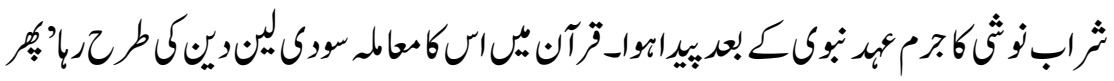

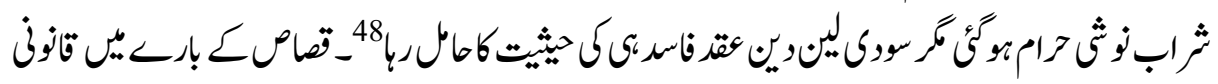

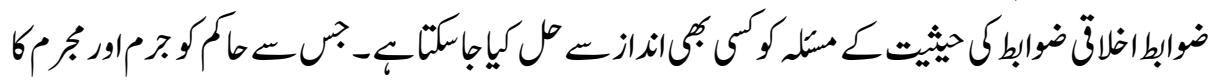

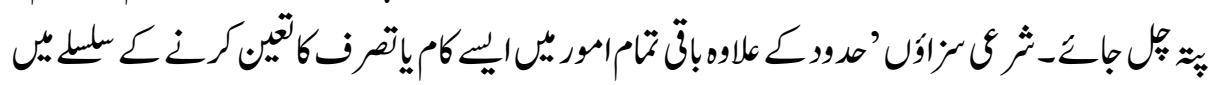

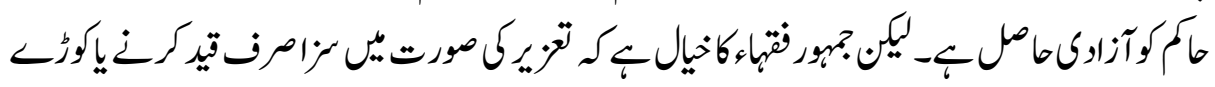

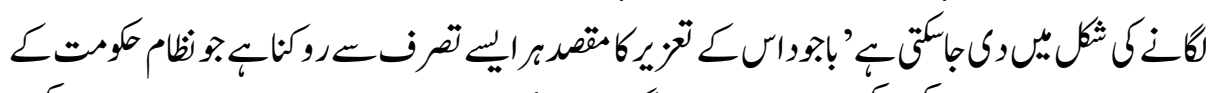

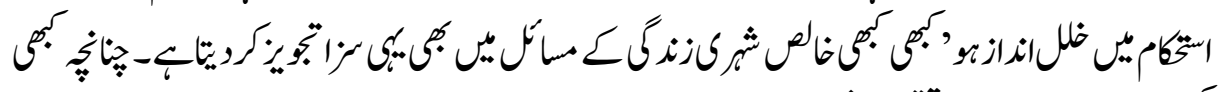

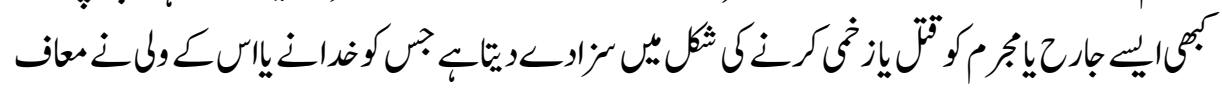

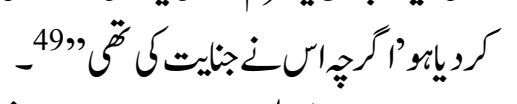

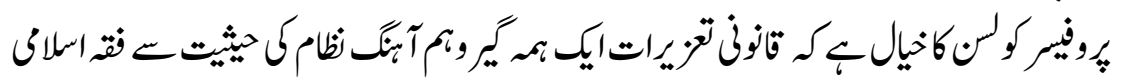

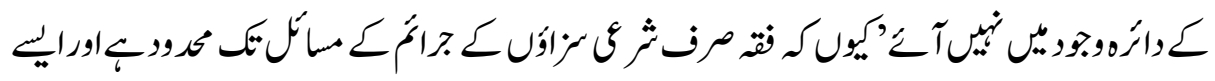

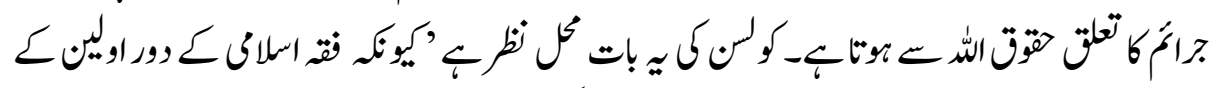

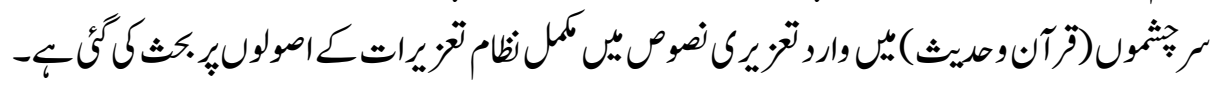

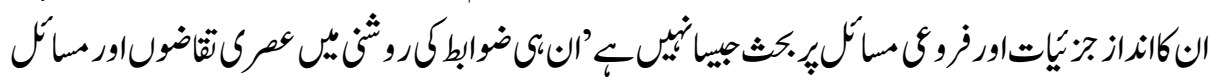

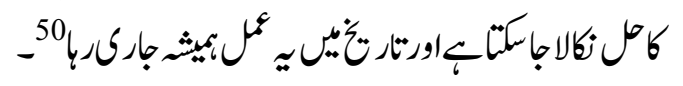

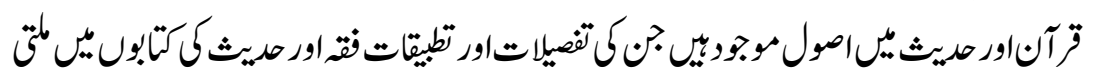

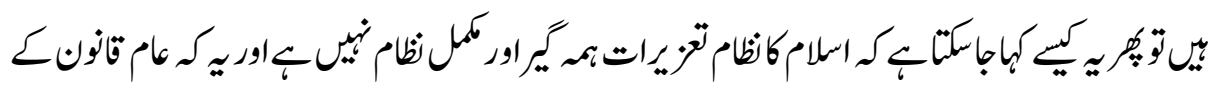

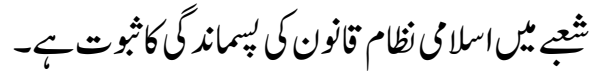




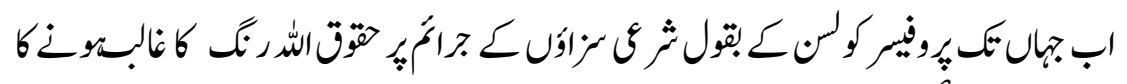

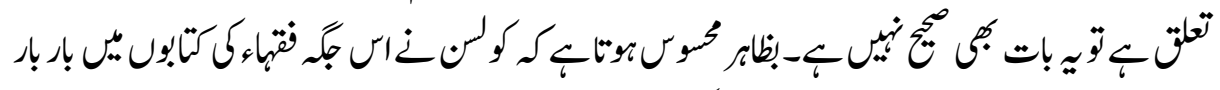

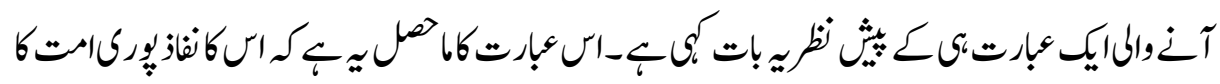
مثرك تن بـ

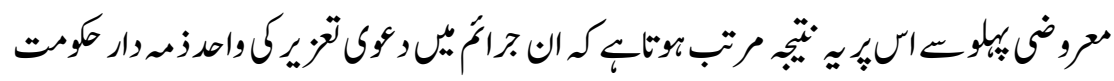

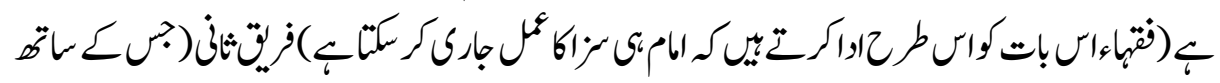

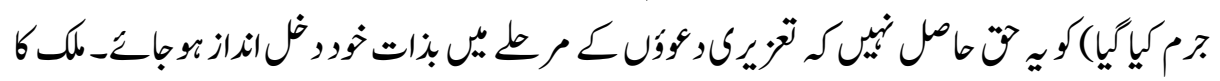

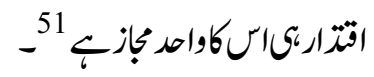

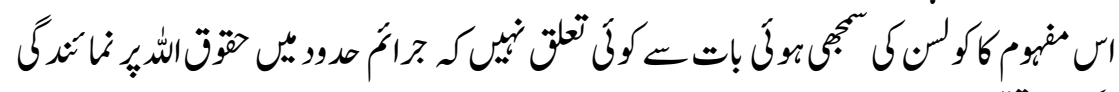

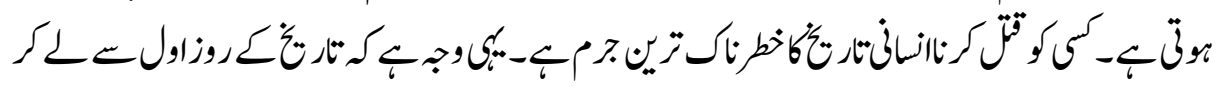

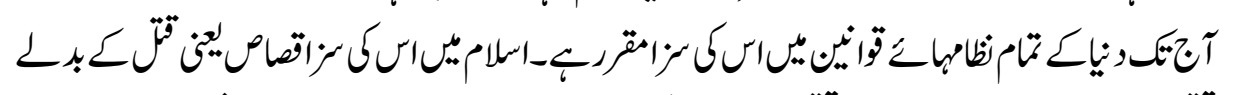

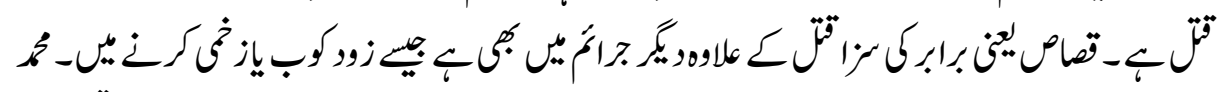

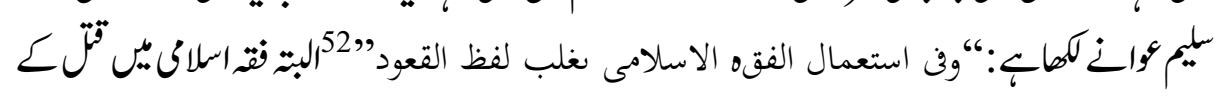

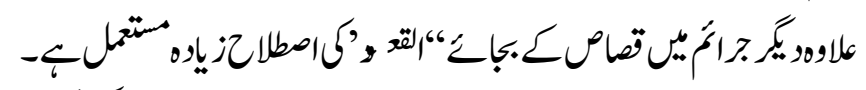

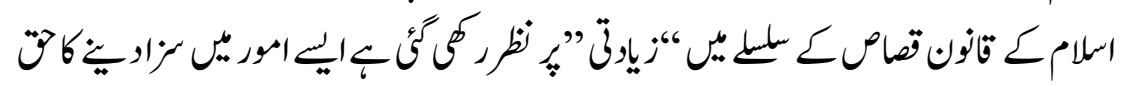

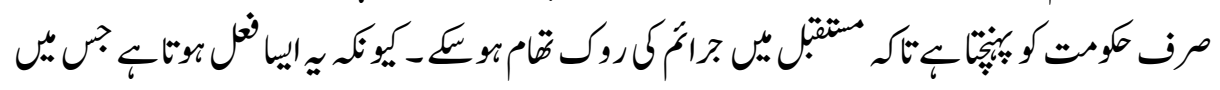

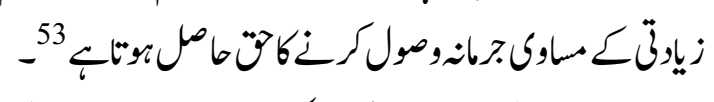

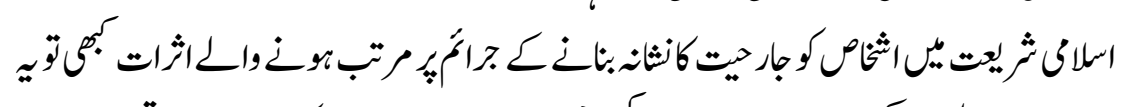

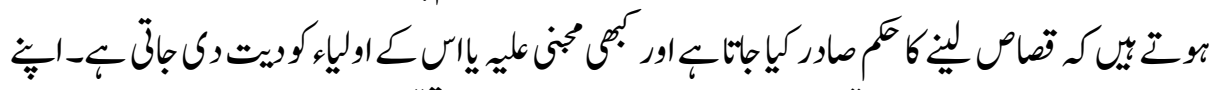

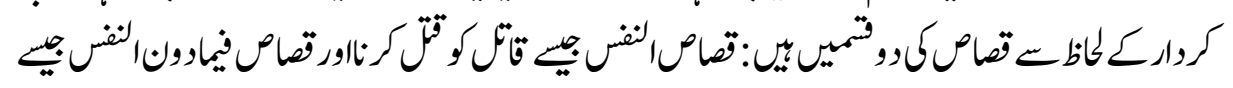

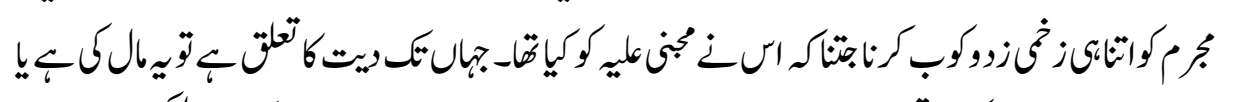

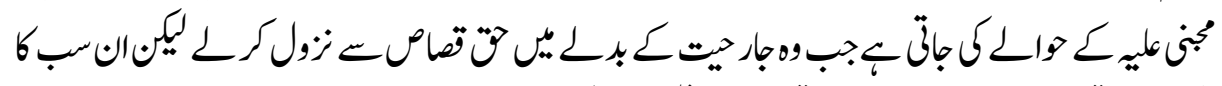

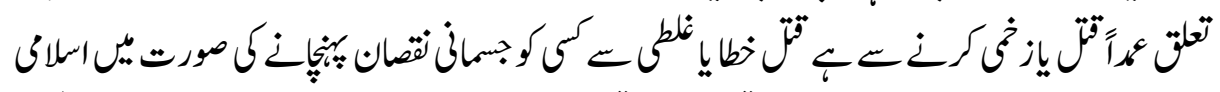

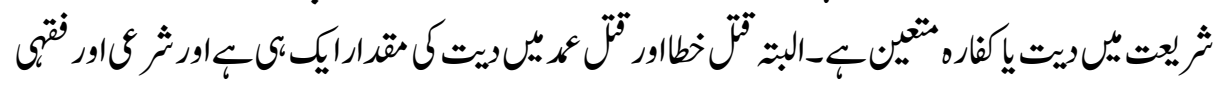




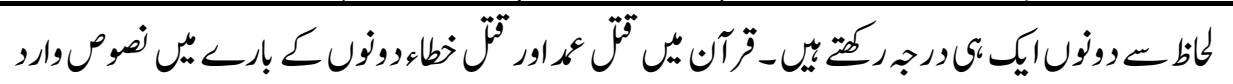

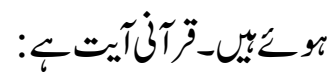

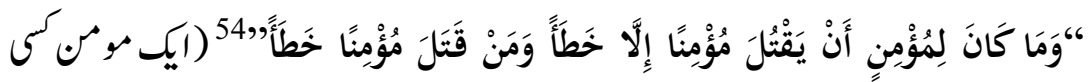

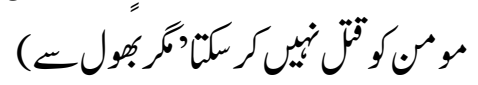

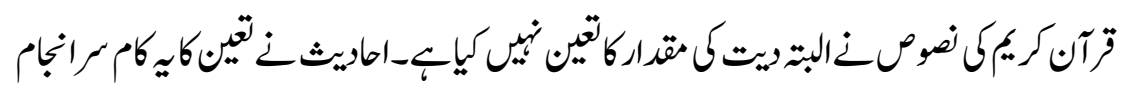

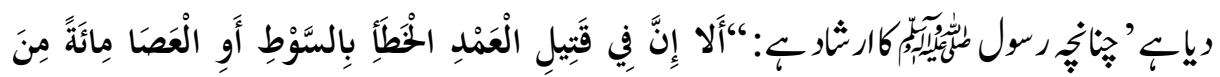

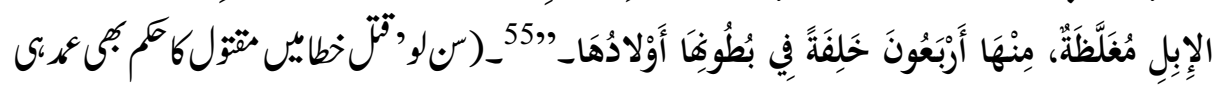

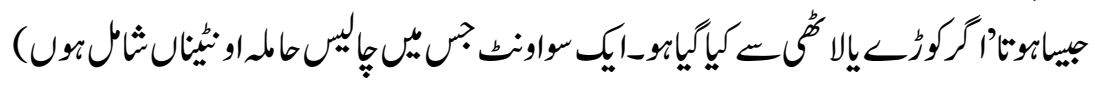

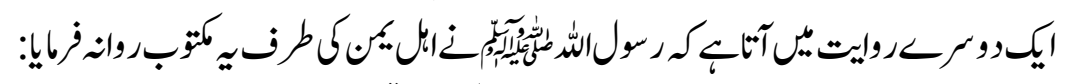

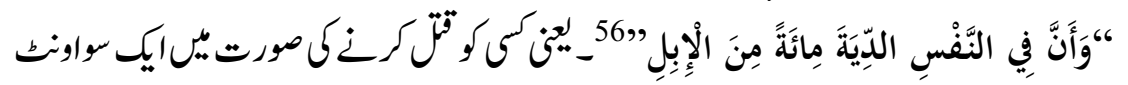

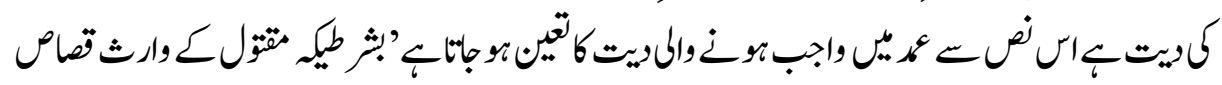

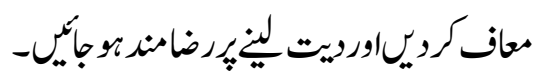

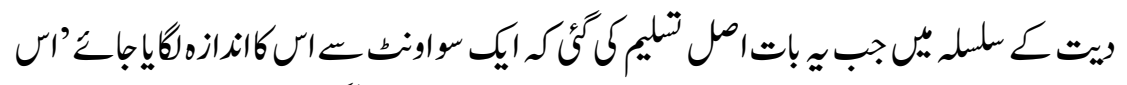

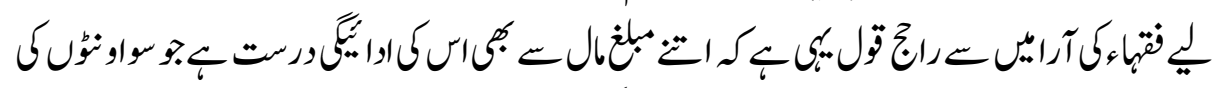

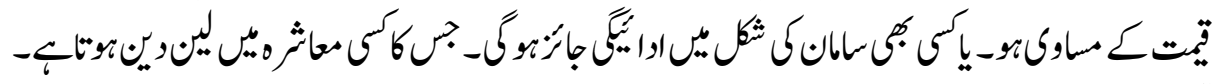

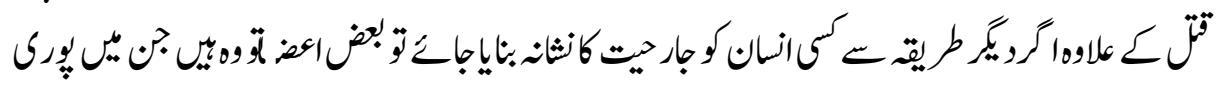

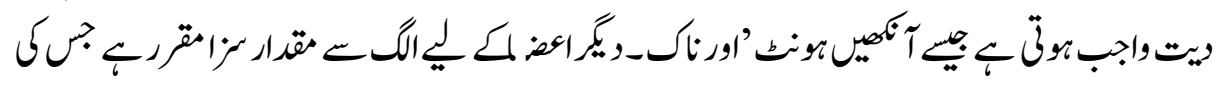

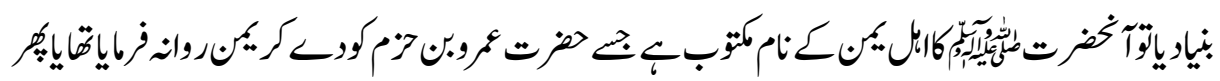

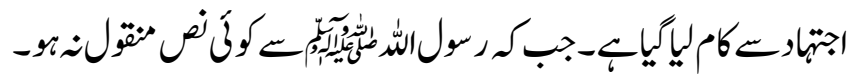

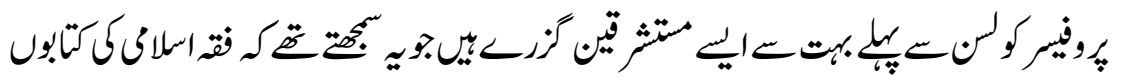

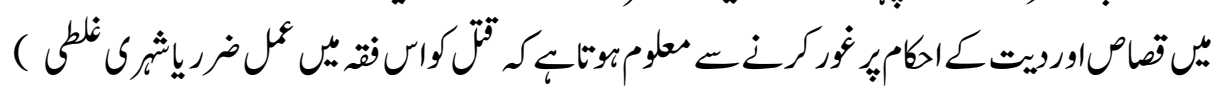
Tort)

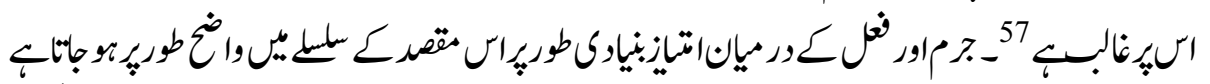

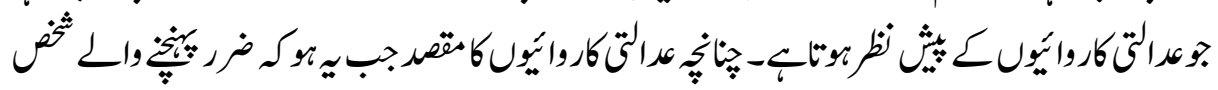




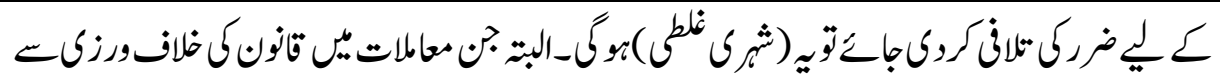

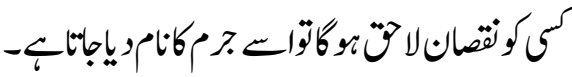

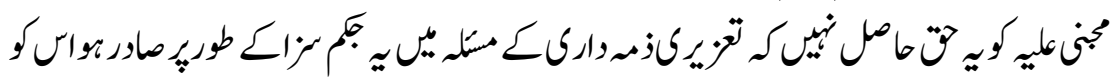

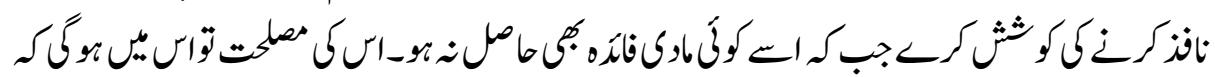

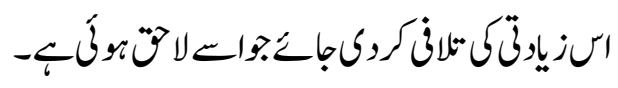

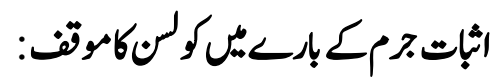

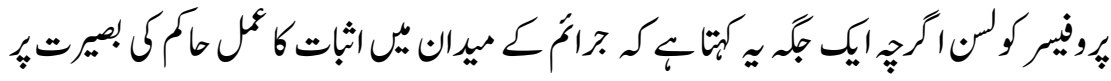

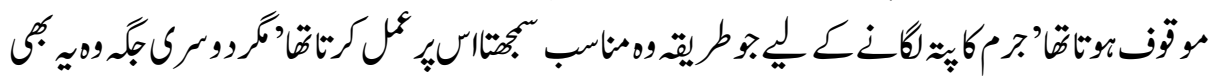

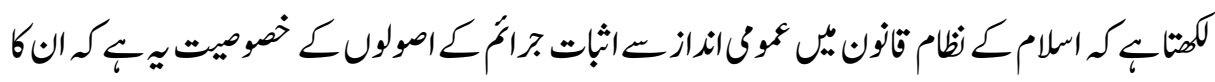

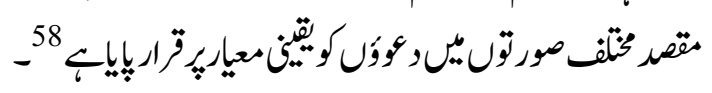

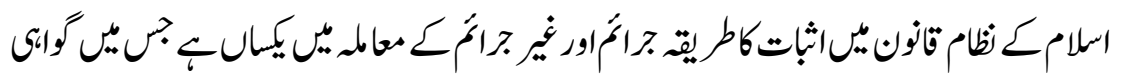

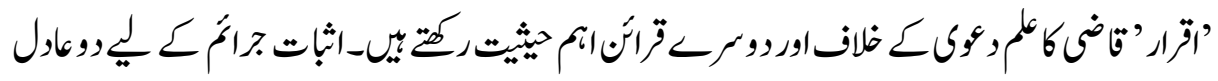

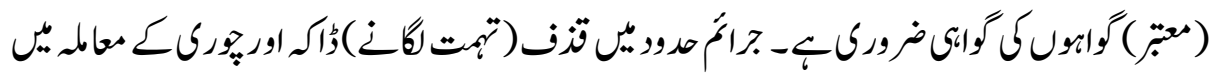

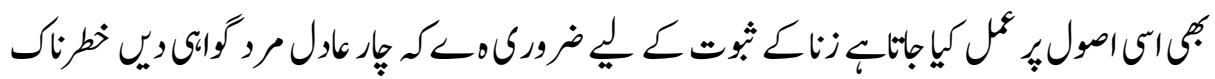

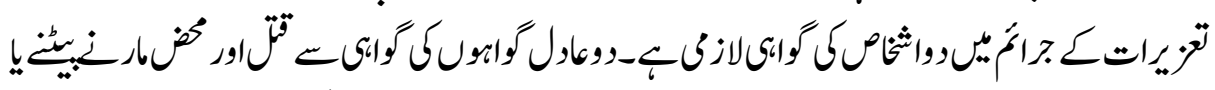

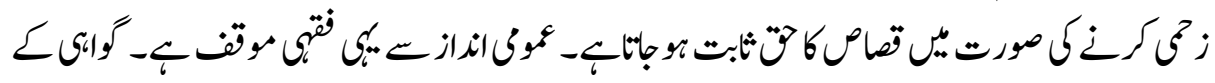

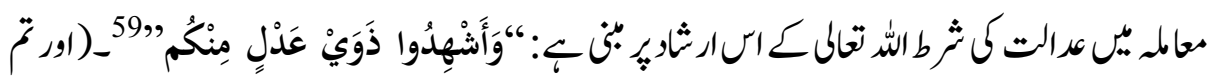

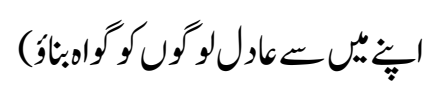

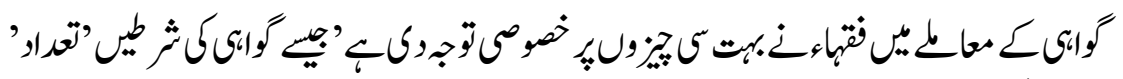

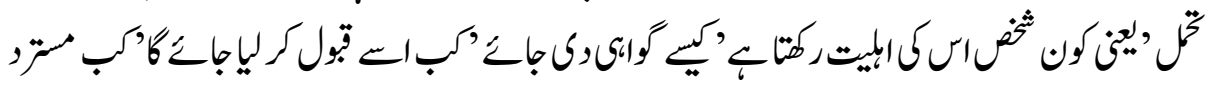

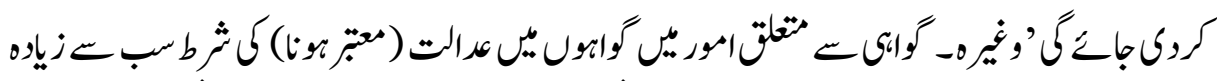

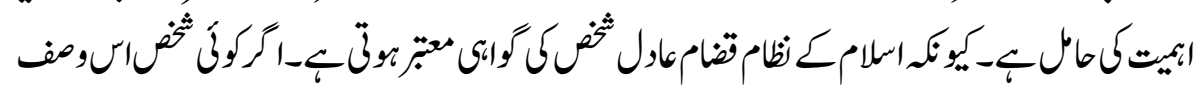

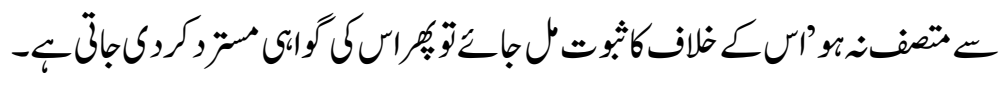




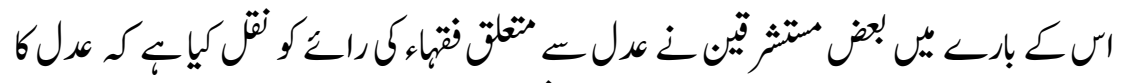

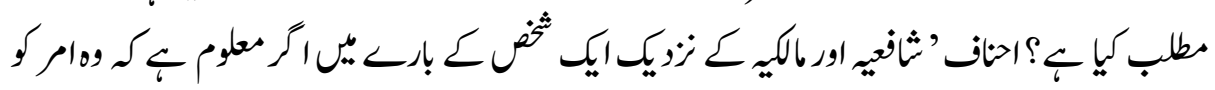

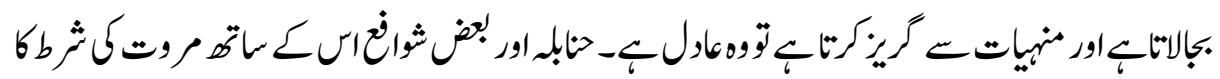

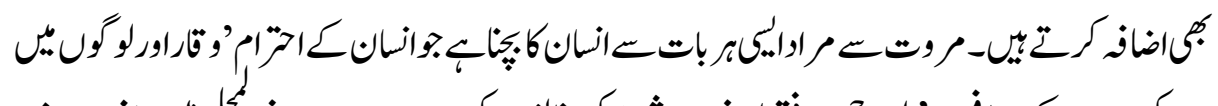

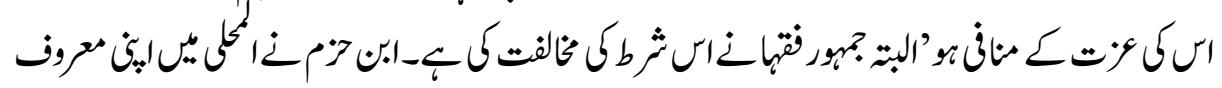

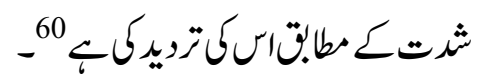

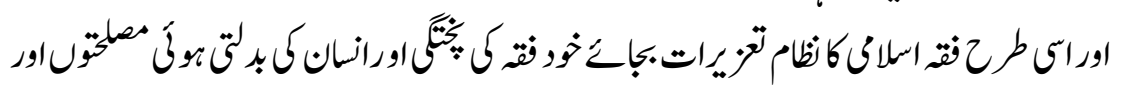

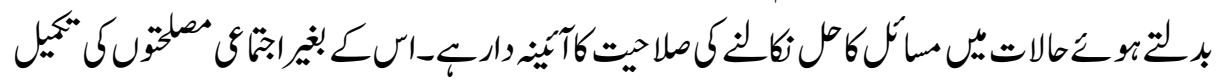

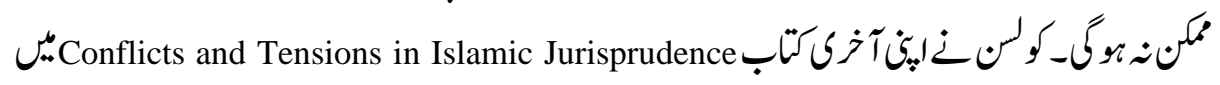

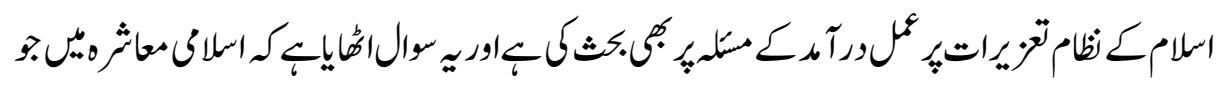

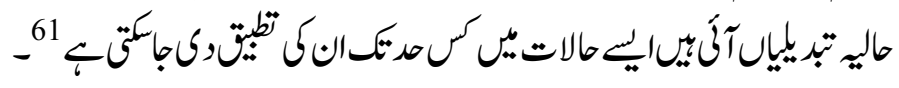
خاصم وثيتج بكث

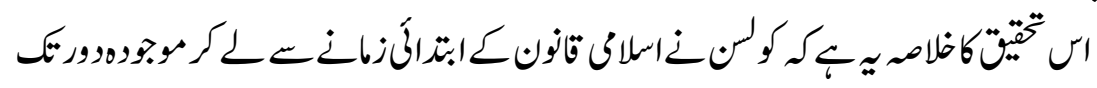

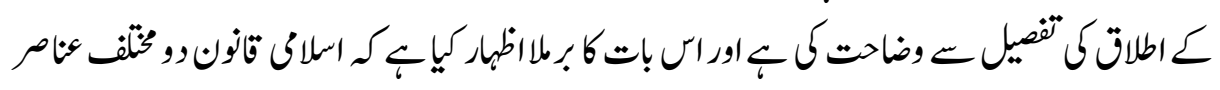

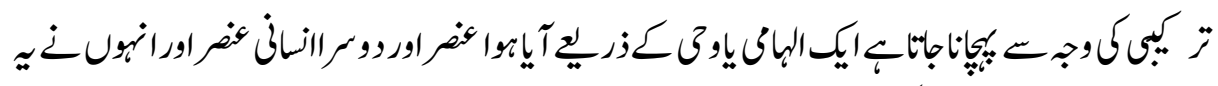

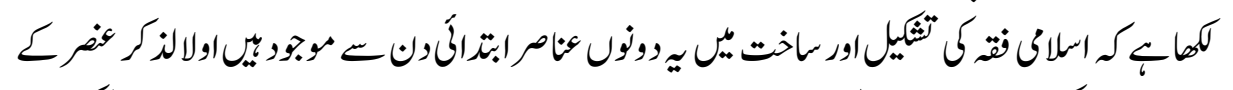

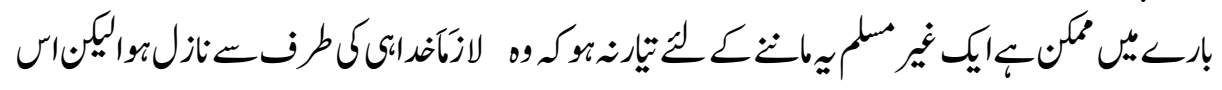

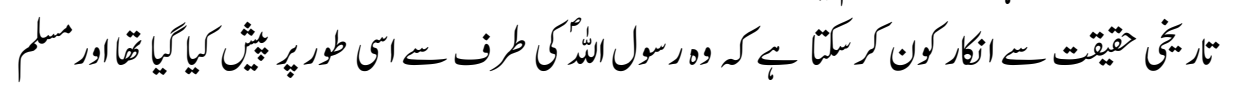

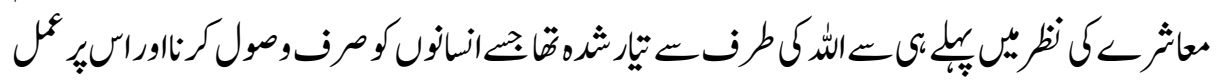

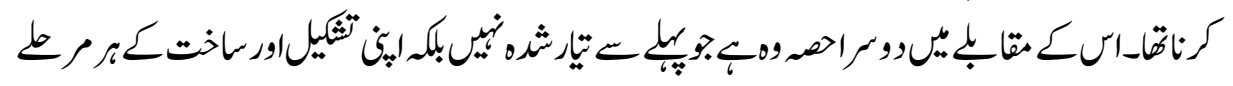

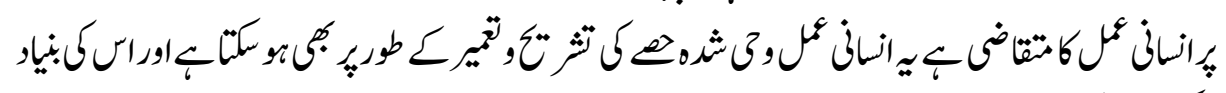

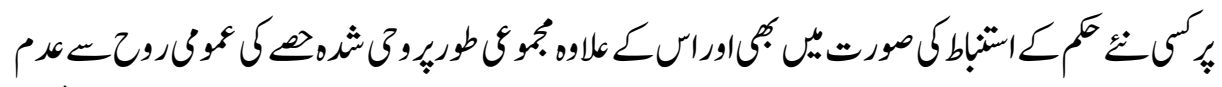

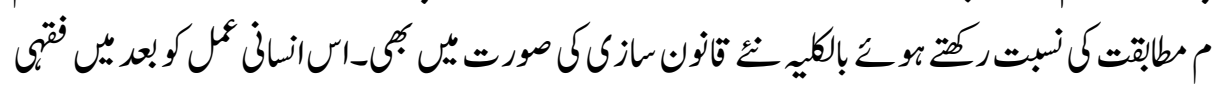

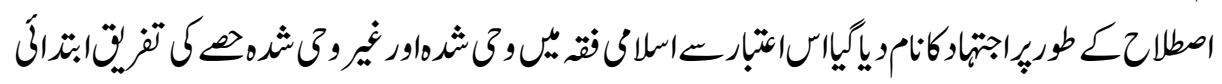




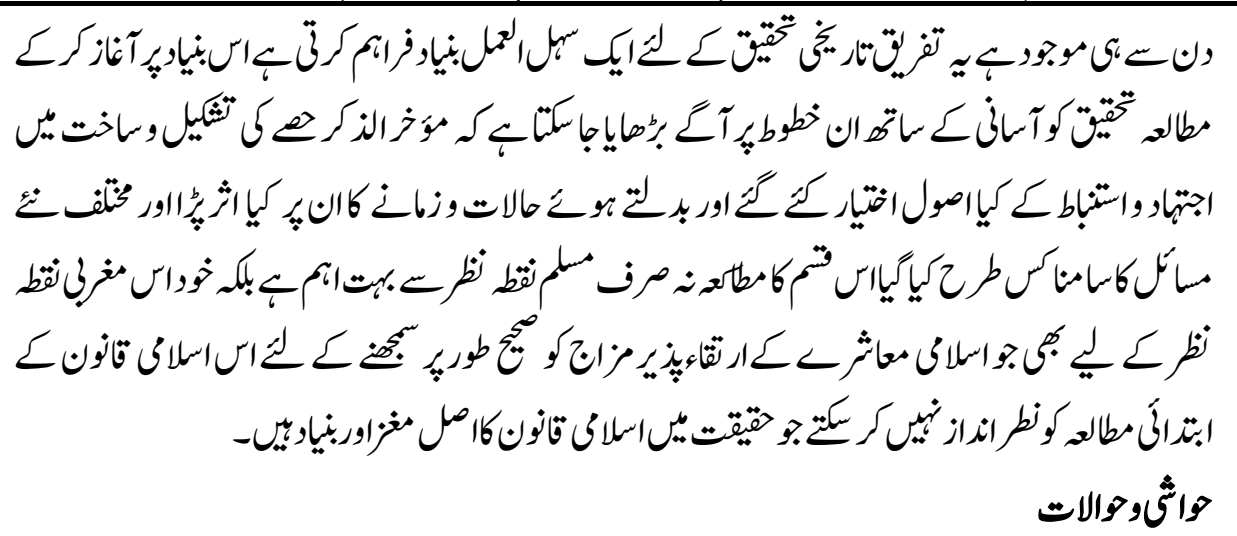

\section{References}

1. See Goldziher for detail

2. Muhammad Ahmad Siraj, tarikh tashria' al Islami, al moassasat al jamia'a lil dirasat, Beirut, 1992, pp. 2-10

3. Ibid

4. Al A'wa, Muhammad Saleem, al nizam al qanoni al Islami,Maktaba al tarbia al Arabi lil dowal al Khalij, al Riyadh, 1985, v1, pp. 253

5. N. J Coulson, Conflicts and Tensions in Islamic Jurisprudence, Chicago, USA, 1969 , pp. 2

6. Muhammad Ahmad Siraj, tarikh tashria' al Islami, al moassasat al jamia'a lil dirasat, Beirut, 1992, pp. 10

7. Ibid

8. N. J Coulson, Conflicts and Tensions in Islamic Jurisprudence, Chicago, USA, 1969 , pp.9

9. Ibid, pp 64

10. Al A'wa, Muhammad Saleem, al nizam al qanoni al Islami,Maktaba al tarbia al Arabi lil dowal al Khalij, al Riyadh, 1985, v1, pp. 257

11. Ibid, pp. 25

12. Ibid, pp. 253

13. Ibid, pp. 254

14. Ibid

15. N. J Coulson, Conflicts and Tensions in Islamic Jurisprudence, Chicago, USA, 1969, pp.11

16. Ibid

17. Ibid, pp. 12

18. Ibid

19. Ibid

20. Ibid, pp. 13,14 
21. Al A’wa, Muhammad Saleem, al nizam al qanoni al Islami,Maktaba al tarbia al Arabi lil dowal al Khalij, al Riyadh, 1985, v1, pp.265

22. Coulson, History of Islamic Law, pp. 5

23. Ibid, pp. 11

24. Al Ibrahim:1

25. Al Isra:9

26. Al A’wa, Muhammad Saleem, al nizam al qanoni al Islami,Maktaba al tarbia al Arabi lil dowal al Khalij, al Riyadh, 1985, v1, pp.263

27. Shibli, Muhammad Mustafa, al madkhil fi al taa'rif bi al fiqh al Islami, pp. 270

28. Al bahiqi, Ahmad bin al Husain, al sunan al kubram darul kutub al ilmia, Beirut,v3, 2003, hadith no 13949

29. Al Maida: 38

30. Al Nisa: 14

31. Shibli, Usool al Fiqh, pp. 99

32. Shafa'I Muhammad bin Idris, al Risalat, darul kutub al ilmia, Beirut, 2001, pp. 102

33. Coulson, History of Islamic Law, pp. 29

34. Al A'wa, Muhammad Saleem, al nizam al qanoni al Islami,Maktaba al tarbia al Arabi lil dowal al Khalij, al Riyadh, 1985, v1, pp. 263

35. Ibid

36. Sayoti, Abdul Rehman, al ishbah wa al nazair, darul kutub al ilmia, Beirut, 1990, pp. 282

37. Al Sarkhashi, al Mabsoot, darul ma'arifa, Beirut, 1993, v6, pp. 36

38. Fi usool al nizam wa al jinai, pp. 270

39. Yahya, Murad, iftiraat al mustashriqin al al islam wa al rado aliha, pp. 398

40. Coulson, History of Islamic Law, pp. 61

41. Ibid

42. Muhammad Ahmad Siraj, tarikh tashria' al Islami, al moassasat al jamia'a lil dirasat, Beirut, 1992, pp. 62

43. Ibid

44. Coulson, History of Islamic Law, pp. 35

45. Muhammad Ahmad Siraj, tarikh tashria' al Islami, al moassasat al jamia'a lil dirasat, Beirut, 1992, pp. 99,100

46. Ibid, pp. 100

47. See manahij al mustashriqin fi al dirasat al Arabia al Islamia, pp 275

48. Ibid

49. Ibid

50. Abdul Qadir Dawa, al tashria' al jinai al islami,

51. Al A'wa, Muhammad Saleem, al nizam al qanoni al Islami,Maktaba al tarbia al Arabi lil dowal al Khalij, al Riyadh, 1985, v1, pp. 76 
52. Ibdi, 283

53. Ibid

54. Al Nisa:92

55. Al bahiqi, Ahmad bin al Husain, al sunan al kubram darul kutub al ilmia, Beirut,v3, 2003, hadith no 15996

56. Muhammad Fawad Abdul Baqi, Moatta Imam Malik, darul shoa’b, Cairo, pp. 530

57. Abderson, J.N. D., Homicide in Islamic Law, 1951, pp.811

58. Yahya, Murad, iftiraat al mustashriqin al al islam wa al rado aliha, pp. 416

59. Al Talaq: 2

60. Yahya, Murad, iftiraat al mustashriqin al al islam wa al rado aliha, pp. 417

61. N. J Coulson, Conflicts and Tensions in Islamic Jurisprudence, Chicago, USA, 1969 